\title{
Making water flow: a comparison of the hydrodynamic characteristics of 12 different benthic biological flumes
}

\author{
Per R. Jonsson ${ }^{1}$, Luca A. van Duren ${ }^{2 *}$, Muriel Amielh ${ }^{3}$, Ragnhild Asmus ${ }^{4}$, Rebecca \\ J. Aspden ${ }^{5}$, Darius Daunys ${ }^{6}$, Michael Friedrichs ${ }^{7}$, Patrick L. Friend ${ }^{8}$, Frédéric Olivier ${ }^{9}$, \\ Nick Pope ${ }^{10}$, Elimar Precht ${ }^{11}$, Pierre-Guy Sauriau ${ }^{12}$ and Estelle Schaaff ${ }^{13}$
}

(1) Department of Marine Ecology, Tjärnö Marine Biological Laboratory, Göteborg University, SE-452 96 Strömstad, Sweden

(2) Netherlands Institute of Ecology, PO Box 140, 4400 AC Yerseke, The Netherlands

(3) Institute de Recherche sur des Phénomènes Hors Equilibre, 12, Avenue General Leclerc, 13003 Marseille, France

(4) Alfred-Wegener-Institut für Polar- und Meeresforschung, Wattenmeerstation Sylt, D-25992 List/Sylt, Germany

(5) Gatty Marine Laboratory, University of St. Andrews, St. Andrews, KY16 8LB Fife, Scotland, UK

(6) Coastal Research and Planning Institute, Klaipeda University, Manto 84, Klaipeda, LT-5808, Lithuania

(7) Marine Biology Department, Rostock University, Albert-Einstein-Strasse 3, D-18051 Rostock, Germany

(8) School of Ocean and Earth Science, Southampton Oceanography Centre, University of Southampton,

Southampton, SO14 3ZH, UK

(9) Station Marine de Dinard, Muséum National de l'Histoire Naturelle, 17, avenue George V, BP 70134, 35801

Dinard, France

(10) Plymouth Marine Laboratory, Prospect Place, The Hoe, Plymouth, PL1 3DH, UK

(11) Max Planck Institut für Marine Mikrobiologie, Celsiusstr 1, D-28359 Bremen, Germany

(12) CREMA (UMR 10 CNRS-IFREMER), Centre de Recherche sur les Ecosystèmes Marins et Aquacoles de

L'Houmeau, Place du séminaire, B.P. 5, F-17137 L'Houmeau, France

(13) Centre d'Océanologie de Marseille, Stn Marine Endoume, F-13007 Marseille, France

*: Corresponding author : Ivanduren@gmail.com

\begin{abstract}
Flume tanks are becoming increasingly important research tools in aquatic ecology, to link biological to hydrodynamical processes. There is no such thing as a "standard flume tank", and no flume tank is suitable for every type of research question. A series of experiments has been carried out to characterise and compare the hydrodynamic characteristics of 12 different flume tanks that are designed specifically for biological research. These facilities are part of the EU network BioFlow. The flumes could be divided into four basic design types: straight, racetrack, annular and field flumes. In each facility, two vertical velocity profiles were measured: one at $0.05 \mathrm{~m} \mathrm{~s}^{-1}$ and one at $0.25 \mathrm{~m} \mathrm{~s}^{-1}$. In those flumes equipped with Acoustic Doppler Velocimeters (ADV), time series were also recorded for each velocity at two heights above the bottom: $0.05 \mathrm{~m}$ and $20 \%$ of the water depth. From these measurements turbulence characteristics, such as TKE and Reynolds stress, were derived, and autocorrelation spectra of the horizontal along-stream velocity component were plotted. The flume measurements were compared to two sets of velocity profiles measured in the field.

Despite the fact that some flumes were relatively small, turbulence was fully developed in all channels. Straight and racetrack flumes generally produced boundary layers with a clearly definable logarithmic layer, similar to measurements in the field taken under steady flow conditions. The two annular flumes produced relatively thin boundary layers, presumably due to secondary flows developing in the curved channels. The profiles in the field flumes also differed considerably from the expected log profile. This may either have been due the construction of the flume, or due to unsteady conditions during measurement. Constraints imposed by the different flume designs on the suitability for different types of boundary layer research, as well as scaling issues are discussed.
\end{abstract}

Keywords Benthic boundary layer - Biological-Physical interaction - Flume tanks - Hydrodynamics methods 


\section{Introduction}

Research on the interaction of water flow with biological processes plays an essential part in many marine and freshwater studies. Examples of such research are: fundamental biodiversity studies (Leonard et al., 1998; Shimeta et al., 2001), transport and accumulation of particles or pollutants in aquatic systems (Butman et al., 1994; Nepf et al., 1997; Widdows et al., 2000), biomechanics (Denny et al., 1985; Riisgård \& Larsen, 1995), applied aquaculture research (Dolmer \& Frandsen, 2002; Hawkins et al., 2001), studies on coastal erosion (Möller et al., 1999) and biofouling (Berntsson et al., 2001). Benthic or bottomdwelling organisms in marine and freshwater systems depend on ambient water flow conditions for their supply of food, oxygen and for the removal of waste products (Fréchette et al., 1989). Water currents also determine fertilisation in the water column of gametes of both plants and animals (Ackerman, 1997; Havenhand \& Svane, 1991) and if and where planktonic larvae can settle (André et al., 1993; Eckman \& Duggins, 1998). Flow velocities and turbulence intensities (i.e. variance to mean ratio) have major effects on sediment structure, erosion and sedimentation processes (Blanchard et al., 1997; Paterson et al., 2000), which in turn have an effect on the local biota and on morphodynamics (Herman et al., 2001). Both large- and small-scale hydrodynamic processes are therefore essential in shaping aquatic communities. Conversely, biological structures such as reefs and large aggregations of bivalves, as well as kelp, seaweeds and seagrass beds, may have a significant effect on the flow regime (Goring \& Nikora, 2002; Granata et al., 2001), whilst sediment characteristics, such as erodability are influenced by e.g. microbial mats (Tolhurst et al., 2000).

The last few decades have seen a remarkable improvement in our understanding of boundary layer processes. The benthic boundary layer is the transitional region in the water column between the solid bed surface and the freely flowing water layers higher up, where the flow is directly influenced by the presence of the bed. In particular technological innovations such as the development of Acoustic Doppler Velocimetry (ADV), Laser Doppler Anemometry (LDA) and Particle Image Velocimetry (PIV) have improved our ability to measure flow velocity and turbulence levels with high spatial and temporal resolution. Our understanding concerning large-scale circulation processes is also relatively well developed. Provided that information is available on the forcing of the large-scale circulation of a system, together with reasonably detailed mapping of the bathymetry, it can be modelled quite accurately. However, as (Boudreau \& Jørgensen, 2001) point out, the interactions between organisms and their physico-chemical environment are extremely complex and hitherto poorly 
understood. The manner by which boundary layer physics affects biology and, equally importantly, how boundary layer hydrodynamics is affected by biota has been identified as one of the most challenging fields of research for the coming decades (Boudreau \& Jørgensen, 2001).

Flume tanks in which water flow can be monitored and manipulated are essential tools for ecologists working in this field. Some research requires careful control of conditions such as: temperature, light level, chemical composition of the water, etc. in a flume tank, whilst in other research a close approximation to the field situation is more important. Some flumes are designed to carefully control and manipulate the hydrodynamic regime, whilst others are designed to investigate the effects of e.g. wave action. Spatial scale is an essential dimension in fluid dynamic processes which also creates methodological problems, particularly to biologists. Physicists often work with scale models and use fluids with modified viscosity to scale their experiments up or down to a convenient size. Living aquatic organisms cannot be scaled up or down, and they generally do not tolerate submersion into fluids other than those forming their normal habitat. Since physical rescaling is often impossible, flume size is a major design issue.

Because the building of medium to large-scale flume tanks is costly, relatively few of these flume tanks are in operation. Seventeen European institutes all working with benthic flume tanks have now been united into a network (BioFlow $\left.{ }^{*}\right)$ to share expertise, information and facilities. Nowell \& Jumars (1987) published an overview of theoretical and experimental considerations for the construction of benthic flumes and the interpretation of data that these set-ups produce. For example, one of their recommendations for the production by flumes of an acceptable bottom boundary layer is that they should have a width to depth ratio of at least 5:1, although 10:1 would be preferable. Flume tanks for biological work tend to be compromises between hydrodynamical optimisations on the one hand, and practical and financial constraints on the other. Each institute has a unique flume facility designed for a specific type of research, and each research group has by definition made some compromises along the way. To examine how these different designs in size and shape compare to each

\footnotetext{
* Flume Facility Có-operation Network for Biological Benthic Boundary Layer Research (BioFlow); EU contract nº: EVR1-CT-2001-20008
} 
other hydrodynamically, and to evaluate the consequences of flume design, we devised an experiment to characterise the benthic boundary layers in these different flumes.

\section{Aim of the experiment}

The flume tanks of the BioFlow consortium are all used to link biological processes to hydrodynamic parameters such as flow velocity, shear velocity, bottom shear stress and drag. Our results, and the interpretation of these results, are influenced directly by

1. The hydrodynamic characteristics of our flume tanks

2. The methods by which the hydrodynamic parameters are measured and calculated This joint experiment was set up to evaluate and compare the characteristics of the different infrastructures within the consortium, and to assess the effect of different methods of calculating the most important hydrodynamic parameters. See Table 1 for a list of symbols and hydrodynamic parameters.

\section{Material and Methods}

Flume tanks may be fitted with a very wide range of equipment for measuring current velocities, turbulence characteristics, turbidity as well as observation equipment for behavioural research, sediment characteristics etc. The flumes within the consortium differ widely in design: some flumes are designed for fresh water, most are designed for seawater; some are temperature controlled, some are laboratory facilities, others are field set-ups and there are facilities that are portable and can be used in the lab as well as in the field. Also, not everyone has access to the same measuring equipment, although all labs had some method for determining flow velocity. There was a considerable array of different flow measurement equipment present, varying from Laser Doppler Anemometry (LDA), Acoustic Doppler Velocimeter (ADV), induction flow meters, ultra sonic equipment to hot film probes. A large part of the participating members had access to an ADV (either Sontek or Nortek), allowing direct calculation of turbulence characteristics.

The joint experiment was therefore split into two parts:

- All participants were to supply two velocity profiles, measured under specified conditions. From these profiles we calculated: boundary layer thickness $(\delta)$; shear velocity $(u *)$; roughness height $\left(\mathrm{z}_{0}\right)$; and, if a measure of variability of the velocity components was available, turbulence intensity (TI). 
- Members with access to an ADV also supplied 4 time series, measured at specified heights and under specified conditions. These data were used subsequently to calculate TI, Reynolds stresses, Turbulent Kinetic Energy (TKE), as well as autocorrelation spectra of the individual velocity components to identify how well developed the turbulence was in the different set-ups.

\section{Environmental characteristics}

All participants supplied details on the flume characteristics, such as basic design, shape of the test section, dimensions and experimental conditions. To reduce sources of variability, member institutes were asked to conduct the experiments at a temperature of $15{ }^{\circ} \mathrm{C}$, salinity of $30 \mathrm{ppt}$, and over a hydrodynamically smooth, preferably hard surface. For some of the setups this was not possible, because the flume was positioned in the field or no salt water was available.

\section{Vertical velocity profiles (all set-ups)}

Two velocity profiles were measured at free stream velocities $\left(U_{\infty}\right)$ of 0.05 and $0.25 \mathrm{~m} \mathrm{~s}^{-1}$. If the measurement device allowed this, the individual velocity components $(u, v$ and $w)$ were supplied, although for some only total velocity magnitude data were available. At least 8 points inside the boundary layer were measured to calculate the law-of-the-wall regression (Schlichting 1979). Most participants were able to supply data points measured outside the boundary layer, into the free stream velocity. In a few set-ups, the boundary layer occupied the whole water column, or the measuring device was unable to reach high enough to establish the boundary layer thickness. Everyone was asked to include in their vertical profiles at least 1 point at $0.05 \mathrm{~m}$ above the bottom surface and one point at $0.2 \mathrm{xH}$ above the bottom surface (where $\mathrm{H}$ = water depth).

One of the set-ups (the one from AWI on Sylt) is a field flume in which velocity cannot actually be regulated, but the tidal flow is led through a channel system where some of the lanes widen and some narrow to decrease or increase flow speed. In this set-up three profiles were measured one in a widening channel, one in a channel that did not change in width and one in a narrowing channel.

In addition to the flume measurements, three profiles were available of ADV measurements in the field. Two profiles (one at $0.07 \mathrm{~m} \mathrm{~s}^{-1}$, and one at $0.22 \mathrm{~m} \mathrm{~s}^{-1}$ ) were measured in the Saltö channel near Tjärnö Marine Biological Laboratory (TMBL) in Sweden. Another profile was 
measured in the Oosterschelde near the Netherlands Institute of Ecology (NIOO) in the Netherlands $\left(\mathrm{U}_{\infty} 0.35 \mathrm{~m} \mathrm{~s}^{-1}\right)$.

\section{Time series measurements (only participants with an ADV)}

A total of four time series were measured: two at each of the previously mentioned velocities, at heights of $0.05 \mathrm{~m}$ above the bottom and at $20 \%$ of the water column depth. At the time the experiments were designed, no overview was present of the characteristics of all the participating flumes, therefore reference heights were picked on the basis of the experience of two of the authors. Subsequently, for some of the set-ups, it was found out that these reference heights were outside the boundary layer. Each time series was measured with a sample frequency of $25 \mathrm{~Hz}$ and for a duration of at least 330 s. This yielded just over 8192 data points for each time series, suitable for spectral analysis, and sufficient to resolve the relevant velocity fluctuations expected in the flumes.

\section{Field measurements}

Nearly all our flume tanks are designed to produce steady, unidirectional flow, with a constant water depth. In estuaries, water depth and flow velocity change continually under the influence of tides. This makes a direct comparison between flume flow and boundary layer flow in the field often difficult. We selected a few data sets collected in the field where, over the course of the measurement, both water depth and flow velocity were quite steady. It is important to note that we do not consider these field measurements to be representative of "the normal field situation". These field profiles simply serve to identify possible scaling mismatches between flume and field, and to identify flow artefacts introduced by flume design.

The data from the Saltö channel in Sweden were collected with a single ADV, measuring consecutive points. Tidal differences in this area are minimal, and the flow is predominantly wind driven over a relatively smooth sand bed. Two data sets were selected, one with a free stream velocity of about $0.07 \mathrm{~m} \mathrm{~s}^{-1}$, and the other at $0.22 \mathrm{~m} \mathrm{~s}^{-1}$, close to the defined experimental conditions. Individual profiles were collected within about 10 minutes, and flow conditions and water depth did not change appreciably over the data collection period.

The data from the Oosterschelde were collected with an array of 3 ADVs. One of these was always fixed to measure at $0.30 \mathrm{~m}$ above the bottom, the other two were repositioned by a diver eventually resulting in a profile up to $30 \mathrm{~cm}$ above the bed, with $1 \mathrm{~cm}$ intervals in the lower $10 \mathrm{~cm}$ and $2 \mathrm{~cm}$ intervals in the upper $20 \mathrm{~cm}$. The sediment in the area where these 
measurements were taken consisted of fine, fairly smooth sand, without any clear ripple structure. The tidal range in the Oosterschelde is nearly $4 \mathrm{~m}$, so water depth and flow velocities tend to change very rapidly. The total profile from this system was collected on the ebb tide within 15 minutes, each measuring point comprising 30 seconds of data. The data from the fixed ADV were used to check that flow velocity did not change significantly over the measuring period. Within these 15 minutes, the water level dropped from $3.50 \mathrm{~m}$ to 3.40 m, i.e. the water column height varied by a maximum of 3\%. A stiff breeze caused nonbreaking surface waves. However, wave oscillations did not penetrate down to the bottom.

\section{Data processing and subsequent calculations}

All the data collected from the various partners were first standardised to SI units. From the flow profiles, shear velocities and roughness length were estimated using the lawof-the-wall regression:

$$
\bar{u}_{(z)}=\frac{u_{*}}{\kappa} \ln \frac{z}{z_{0}}
$$

where $\bar{u}_{(\mathrm{z})}$ is the mean velocity at height $\mathrm{z}, u_{*}$ is the shear velocity, $\kappa$ is the Von Karman constant $(\kappa \approx 0.4)$, $\mathrm{z}$ is the distance from the bottom and $\mathrm{z}_{0}$ is the roughness height.

For all the datasets from which a measure of the standard deviation was supplied for the velocity components, we calculated the turbulence intensity at $0.05 \mathrm{~m}$ above the bottom and at $0.2 \mathrm{xH}$, according to the following equation:

$$
T I=100 \times \frac{\sqrt{(s u)^{2}+(s v)^{2}+(s w)^{2}}}{\sqrt{u^{2}+v^{2}+w^{2}}}
$$

giving a relative measure for turbulence ( $s$ indicates standard deviation, modified after (Gambi et al., 1990). Some datasets contained only 2D data, in which case the $w$ component was ignored.

From the ADV time series, we estimated the Turbulent Kinetic Energy (TKE). This parameter can be defined as the turbulent energy content per unit mass $\left(\mathrm{J} \mathrm{kg}^{-3}\right)$. It can be estimated from the fluctuating velocity components:

$$
1 / 2 \rho\left(u^{\prime 2}+v^{\prime 2}+w^{\prime 2}\right)
$$

Since the density $(\rho)$ is more or less constant over the range of scales considered in our flume 
experiments, it is left out of the equation, and we end up with the units $\mathrm{m}^{2} \mathrm{~s}^{-2}$. Furthermore we calculated the momentum flux in the vertical direction, which is also calculated from the velocity fluctuations:

$$
-\rho \overline{u^{\prime} w^{\prime}}
$$

This turbulence driven momentum flux is known as Reynolds stress.

Finally, autocorrelation spectra on the along stream component $(u)$ were calculated for both velocities, and at each of the two reference heights, using fast Fourier transformation. If no energy is added by the mean flow, nor removed by viscous dissipation, the energy flux across the intertial subrange is constant and equal to the energy dissipation rate at the small-scale end of the spectrum. The spectrum of TKE depends only upon the dissipation rate. Dimensional analysis shows that in a fully turbulent regime this spectrum falls off proportional to $\mathrm{k}^{-5 / 3}$, where $\mathrm{k}$ is the wave number. This is known as the Kolmogorov $-5 / 3$ law (Tritton, 1988; Tennekes \& Lumley, 1999). Using Taylor's “frozen turbulence” hypothesis, which allows time scales to be converted into spatial scales, we can use the auto-spectra of the velocity components measured with an ADV to examine if the slope in the inertial subrange follows the $-5 / 3$ law (Nikora et al., 1997). This allows us also (if the measuring frequency is sufficiently high) to identify the length scale of the eddies below which energy dissipates due to viscosity. This size range of the smallest eddies in the flow regime is known generally as the Kolmogorov length scale.

\section{Brief description of all flumes involved in this experiment, and identification of measuring equipment}

Thirteen institutes provided data series from twelve different flume facilities. Seven of these facilities have straight flume tanks:

- Gatty Marine Laboratory, University of St. Andrews in the UK (GML)

- Tjärnö Marine Biological Laboratory, Sweden (TMBL)

- Centre de Recherche en Ecologie Marine et Aquaculture de l'Houmeau, France (CREMA)

- The Marine Biology Section of the University of Rostock, Germany (ROSTOCK)

- Klaipeda Coastal Research and Planning Institute, Lithuania (KUCORPI)

- Max Planck Institute for Marine Microbiology, Germany (MPI-MM) 
- The Centre d'Océanologie de Marseille (COM) and the Institute de Recherche sur les Phénomènes Hors Equilibre (IRPHE), France supplied datasets on the same flume tank (LOB).

The Rostock facility, as an example of a straight flume is pictured in Fig. 1a.

Two facilities have racetrack flumes (see Fig. 1b with a drawing of the NIOO flume as an example):

- Netherlands Institute of Ecology, (NIOO)

- The Station Marine de Dinard belonging to the Muséum National de l’ Histoire Naturelle, France (MNHN).

Two institutes supplied data from annular flumes (see Fig. 1c for an example from the SOC flume):

- Southampton Oceanography Centre, belonging to the University of Southampton, UK (SOC)

- Plymouth Marine Laboratory, UK (PML)

One institute supplied data from a system of field flumes (see Fig. 1d for the design of this specific flume).

- Alfred Wegener Institut für Polar und Meeresforschung located on the island of Sylt, Germany (AWI).

The AWI set-up consists of a series of channels, oriented along the direction of the main tidal flow. Three of these channels are of continuous width, but are constructed in a zigzag pattern, three channels widen before the test section, decelerating the tidal flow, and three channels narrow down in front of the test section, accelerating the flow (Fig. 1d).

The dimensions of the various facilities are listed in Table 2. For flume length the distance is taken from the entrance to the straight test section until the measuring device. Based on these dimensions and on the free stream velocities that were used in the experiments we calculated two types of descriptive Reynolds numbers for each flume (Table 3). First of all a local Reynolds number $\left(\mathrm{Re}_{\mathrm{x}}\right)$ :

$$
\operatorname{Re}_{x}=\frac{U_{\infty} x}{v}
$$

where $U_{\infty}$ is free-stream velocity, $\mathrm{x}$ is the distance the flow has travelled from the entrance of the test section to the measuring point and $v$ signifying the kinematic viscosity of the fluid, which for sea water is in the order of magnitude of $1.3610^{-6} \mathrm{~m}^{2} \mathrm{~s}^{-1}$ (Schlichting 1979). This 
parameter was not relevant for the annular flumes since these devices lack any entrance conditions. Secondly we calculated a channel Reynolds number $\left(\operatorname{Re}_{c}\right)$, based on the hydraulic diameter of the channel (4 x cross sectional area/wetted perimeter).

\section{Results}

\section{Vertical velocity profiles and boundary layer thickness}

Vertical velocity profiles for all flumes are presented in Figs. 2 and 3 for the free-stream velocities 0.05 and $0.25 \mathrm{~m} \mathrm{~s}^{-1}$, respectively. Boundary layer thickness was derived from visual inspection of the semi-log graphs. For some flumes it was not possible to follow the velocity profile up to the water surface (air-water interface), and in the LOB flume the boundary layer extended all the way up to the water surface. Consequently, it was not always possible to estimate the boundary layer thickness. In Table 4 the water depth, boundary layer thickness and boundary layer Re (using the boundary layer thickness as the relevant length scale) are summarised for all velocity profiles. For the straight and racetrack flumes, boundary layers varied between 0.03-0.15 m for both free-stream velocities. No consistent difference in boundary layer thickness between the 2 velocities could be detected although, theoretically, a decrease of about $27 \%$ is expected for the higher velocity. The 2 annular flumes (SOC and PML) produced velocity profiles with a detectable, but compressed $(<0.01$ $\mathrm{m}$ ) boundary layer. Boundary layers in nature may be even thinner, e.g. during the sheet flow of flood and ebb when the water is only centimetres deep, but Table 4 shows that the boundary layers in the annular flumes were also thin relative to the water depth. The profiles measured in the AWI field flumes showed boundary layers with variable velocity gradients. In these profiles the extent of the boundary layers is sometimes difficult to determine exactly, but in most profiles the boundary layer thickness appears to be between 0.1 and $0.2 \mathrm{~m}$. Figure 4 shows that the boundary layers measured for natural flows in the field were well defined and presumably extended beyond the range of measurements. Although the bed was fairly smooth at both locations where the measurements were taken, effects of upstream roughness affecting the shape of the boundary layer cannot be excluded.

The majority of the velocity profiles showed a logarithmic layer in the lower part of the boundary layer and the fit to the log-linear relation (law-of-the-wall, eq. 1) between local velocity and height above the bed was good to excellent with a few exceptions (Fig. 5). The most notable exceptions were the 2 annular flumes with their thin boundary layers where it 
was not possible to measure enough data points to obtain a log-linear relationship with a good fit. Also in the field flumes the profiles did not fit the "standard" log profile very well. The regression lines of log-linear plots for all three types of channels in this facility showed an $\mathrm{r}^{2}$ of around 0.6. The variability of the profiles is almost certainly due to the fact that these profiles were all measured in unstable flow conditions. It is therefore difficult to make a direct comparison between these set-ups and the other flumes. Therefore we have excluded the data from the field flumes from further comparison of derived flow parameters, such as shear velocity.

\section{Shear velocity}

Shear velocity $(u *)$ was estimated from regressions of measured velocity profiles using the law-of-the-wall model. The straight and racetrack flumes with a clear logarithmic layer produced shear velocities between $0.0016-0.0048 \mathrm{~m} \mathrm{~s}^{-1}$ at the lower velocity, and 0.0053 $0.015 \mathrm{~m} \mathrm{~s}^{-1}$ at the high free-stream velocity (Fig. 6). On average this is 4.1 and $5.9 \%$ of the tested free-stream velocities, respectively. This level of shear velocity is expected from a smooth turbulent flow. The shear velocities estimated for the 2 annular flumes are very uncertain since the estimates of the regression slope are based on only a few measurements within the thin boundary layer. Many of the flumes show similar shear velocities compared to estimates from field boundary layers (Fig. 4).

\section{Roughness length}

The regression of the velocity profiles based on the law-of-wall model also estimates the roughness length, a parameter correlated to bed roughness $\left(\mathrm{z}_{0}\right)$. Figure 7 shows that the roughness length for the flume flows differs substantially, by about 4 orders of magnitude. Large variability is expected since roughness length is estimated from the intercept of the law-of-the-wall model and is very susceptible to error in the slope estimate and the numer of points used.

\section{Comparison of all boundary layers}

Due to the differences in water level it is difficult to make a fair direct comparison between the boundary layers in all tanks. A common way of dealing with this problem is by making both the velocity and the height above the bed dimensionless. Dimensionless velocity $\left(\mathrm{u}^{+}\right)$is obtained by dividing the local velocity (u) by the shear velocity $(\mathrm{u} *$ ). Dimensionless height 
$\left(\mathrm{z}^{+}\right)$is calculated as $\frac{u_{*} Z}{v}$, where $v$ is kinematic viscosity (Dade et al., 2001). In figure 8a the dimensionless boundary layer for all straight and racetrack flumes are plotted. The annular flumes are left out here. All flumes have a clear straight section in the boundary layer, indicating the presence of a log layer. Most flumes have depths between 10 and $50 \mathrm{~cm}$. We have constructed an ideal boundary layer assuming a water column with a fully developed boundary layer of $25 \mathrm{~cm}$ and a free-stream velocity of $0.25 \mathrm{~m} \mathrm{~s}^{-1}$. This layer has a value of $\mathrm{u} *$ of about $0.01 \mathrm{~m} / \mathrm{s}$. Assuming a $\mathrm{z}_{0}$ of $0.00001 \mathrm{~m}$ (a very smooth bed with little roughness), we created a boundary layer with the law of the wall and calculated its $\mathrm{u}^{+}$and $\mathrm{z}^{+}$. This theoretical boundary layer is used to compare the boundary layers for the other flume tanks to. The slopes of the log layers in the flumes are all very similar and are all also similar to that of the theoretical boundary layer. There are conspicuous differences in the offsets though. In theory, the points of all dimensionless boundary layers over a flat plate should collapse into one single line (Dade et al., 2001). For some flumes (NIOO and KUCORPI) the points from both velocities indeed appear to do this. However, for most other flumes there is a difference between the two datasets. For comparison, the data from the field measurements are shown in figure 8b. These also show a similar slope compared to the theoretical one. There is a difference in offset between the Oosterschelde and the Saltö channel, but the data from different velocities in the latter collapse on one line.

\section{Turbulence intensity}

Turbulence intensity (TI) is shown for 2 heights and for the 2 tested free-stream velocities in Fig. 9. The 2 heights generally gave similar estimates. Except for the ROSTOCK and KUCORPI flumes, the TI tended to decrease when increasing the free-stream velocity. TI was $10-30 \%$ at $0.05 \mathrm{~m} \mathrm{~s}^{-1}$ and $5-35 \%$ at $0.25 \mathrm{~m} \mathrm{~s}^{-1}$. Both the ROSTOCK and the KUCORPI flume are not designed to operate at flow velocities above $0.2 \mathrm{~m} \mathrm{~s}^{-1}$. To reach $0.25 \mathrm{~m} \mathrm{~s}^{-1}$, they had to run their engines at extreme speeds and ROSTOCK also lowered the water level in their flume. The field measurements of TI were generally higher than those found in the flumes, in particular at the higher free-stream velocity.

\section{Turbulent kinetic energy}

Not surprisingly, a similar pattern as that for TI was found for the turbulent kinetic energy (TKE), illustrated in Figs. 10a and b. For the flumes that could produce 3-dimensional flow data at $25 \mathrm{~Hz}$ TKE varied from $1.7 \times 10^{-5}-9.5 \times 10^{-5} \mathrm{~m}^{2} \mathrm{~s}^{-2}$ at $0.05 \mathrm{~m} \mathrm{~s}^{-1}$ and from $1.9 \times 10^{-4}$ - 
$2.0 \times 10^{-3} \mathrm{~m}^{2} \mathrm{~s}^{-2}$ at $0.25 \mathrm{~m} \mathrm{~s}^{-1}$. The ROSTOCK and KUCORPI flumes produced very high TKE at $0.25 \mathrm{~m} \mathrm{~s}^{-1}$, which is again, probably caused by the fact that these flumes are not designed for flow speeds above ca $0.15 \mathrm{~m} \mathrm{~s}^{-1}$. Figures 10c and d, show TKE normalised to the square of the local velocity, to compare the flumes, while removing the effect of the differences in velocity at the reference heights. On a normalised scale, the TKE measurements in the NIOO, SOC and PML flumes were higher at the lower free-stream velocity. In the $0.05 \mathrm{~m} \mathrm{~s}^{-1}$ experiments, the TKE was similar to that found in the field. However, at the faster flow speed, TKE in the field was generally higher than in most flumes.

\section{Reynolds stress}

In the boundary layer momentum should be transported from the water column towards the bed. Most flumes indeed show negative Re stress in the boundary layer, although the magnitude differs considerably (Fig. 11). This can partly be explained by the dependence of Re stress on the relative position within the boundary layer, with Re stress decreasing when moving up through the boundary layer (Fig. 12). Because of differences in boundary layer thickness among flumes, the fixed heights where data were collected to estimate Re stress will represent different relative positions in the boundary layer. On a velocity-normalised scale the KUCORPI flume produces large Re stresses at the lower speed, and both KUCORPI and ROSTOCK flumes show high values at the faster flow speed. This indicates that there is much added friction in these flumes. As indicated before, both these flumes were not designed to run at such high velocities. The added friction may have been introduced by surface ripples, caused by running these flumes at inappropriate speeds. Lowering the water level to reach $0.25 \mathrm{~m} \mathrm{~s}^{-1}$ in the ROSTOCK flume, will also have compressed the boundary layer and increased the Reynolds stress.

\section{Calculation of shear velocity from Re stress and TKE}

Estimates of Re stress or TKE can be used as an alternative to the regression analysis of vertical velocity profiles to estimate shear velocity (Kim et al., 2000). This is particularly useful in cases where it is impossible to get a sufficient amount of measurements in the boundary layer for an accurate estimate of the slope of the regression line. These calculations are based on the assumption that in the lower part of a fully turbulent log layer shear velocity $(\mathrm{u} *)$ is related to Re stress as:

$$
u_{*}=\sqrt{-\overline{u^{\prime} w^{\prime}}}
$$

and to TKE as: 


$$
u_{*}=\sqrt{c_{1} \times T K E}
$$

where $c_{1}$ is a proportionality constant with an approximate value of 0.2 (Kim et al., 2000). Both methods are based on the fluctuating velocity components and give very similar results in their estimates of $\mathrm{u} *$ (Fig 13a). The only real outliers (encircled in the graph) are the two data points from the ROSTOCK flume at the high velocity. Again, this is very likely a consequence of the extreme measures they took in order to reach the high flow speed. For all other series the estimates of $\mathrm{u} *$ using either the covariance method (i.e. based on the Reynolds stress) or the TKE method are very similar, although in the two higher velocity field measurements the estimates from TKE are relatively large, compared to those derived by the covariance method. We also compared estimates of shear velocity calculated from regressions of velocity profiles to estimates from the Re stress and TKE (Fig. 13b). At $0.05 \mathrm{~m}$ $\mathrm{s}^{-1}$ the estimates are close to the $45^{\circ}$ line, i.e. there is a very good agreement. At $0.25 \mathrm{~m} \mathrm{~s}^{-1}$ the estimates are less similar. Generally, in the field, calculations from Re stress and TKE gave higher estimates of shear velocity (star symbols), while in the flumes Re stress gave lower estimates compared to the regressions of the velocity profiles. In part, this may be explained by the fact that some measurements of Re stress and TKE were taken too high up in the flume boundary layer, whilst in the thick boundary layers found in the field, the measurements fell well within the constant stress layer. When measurements of flumes with thin boundary layers (i.e. 3 points from the annular flumes) and data series from flumes running at abnormally high speeds (KUCORPI and Rostock University at $0.25 \mathrm{~m} \mathrm{~s}^{-1}$ ) are removed, the fit is much better (Fig. 13c).

\section{Autocorrelation spectra of turbulent velocities}

Time series of turbulent velocities sampled at $25 \mathrm{~Hz}$ were collected from 8 flumes and for one field data set. All autocorrelation spectra clearly show that flow was turbulent for both free-stream velocities (Fig. 14). For most flumes there is an inertial sub-range region corresponding well to the expected slope of $-5 / 3$. However, for some of the data series the inertial sub-range is flatter, e.g. the GML, PML and LOB flumes. This flatter spectrum indicates either that energy in this range is added by the mean flow, or that the level of turbulent energy is so low that the spectrum is influenced directly by the Doppler noise error of the ADV (Nikora \& Goring, 1999). The upper turbulence scale, i.e. the scale of the largest eddies in a flume, will be determined partly by the flume dimensions (Sanford, 1997). Fig. 15 indicates that there is a relationship between flume width and the upper turbulence scale, 
although this relationship is not quite significant $(p=0.06)$. In the calculation, one outlier (see top of the graph) was omitted. This represents the high velocity data point from KUCORPI. As pointed out previously, this flume was not designed for such high velocities, and the upper turbulence scale may have been influenced by surface waves, even though the inertial subrange had a slope very close to $-5 / 3$.

\section{Secondary flow}

Flumes are usually designed to produce a unidirectional flow with a minimum of large-scale, cross-channel (secondary) flows. Secondary flows may be caused by bends, propulsion devices, poor entrance/exit conditions and, as pointed out by Nowell and Jumars (1987), unfavourable ratios between water depth and channel width. For straight flumes the distance from entrance to the working section has to be sufficiently long to allow dissipation of secondary flows caused mainly by bends, change in channel geometry, and propulsion. However, annular flumes do not have a straight section, and due to the elevation of the water level on the outside of the channel, there will be a cross-channel pressure gradient driving secondary flow. As a test of the presence of significant secondary flow patterns, we estimated the covariance between the $v$ and $w$ velocity components in all flumes where 3-dimensional flow measurements were provided. Covariance between the $v$ and $w$ components was small for all flumes at $0.05 \mathrm{~m} \mathrm{~s}^{-1}$. At $0.25 \mathrm{~m} \mathrm{~s}^{-1}$, the annular flumes (SOC and PML) showed a significant increase in the covariance indicating secondary flow structures (Fig. 16). However, the mean u component was the primary component, representing $>98 \%$ of the horizontal mean flow ( $\mathrm{u}$ and $v$ components). Also, the covariance estimated for the KUCORPI and the ROSTOCK flumes suggests secondary flow, which may be one cause of the high values of TKE found (Fig. 10). In the ROSTOCK flume the secondary flows are probably caused by the propeller hub, which stretches throughout the water column. Finally, the GML flume shows significant covariance between the $v$ and $w$ components.

\section{Discussion}

\section{Methodology}

Before the experimental protocol was distributed among the participating laboratories within BioFlow, no inventory was available describing the design and dimensions of the different facilities. Consequently selection of the two heights and velocities used in the experiment was based upon the experience of a few scientists using their own flumes. It turned out that some 
of the flumes were not designed to run at velocities as high as $0.25 \mathrm{~m} \mathrm{~s}^{-1}$. In the ROSTOCK flume the water level was lowered, and the motor set to run at full power to reach the desired free-stream velocity. The KUCORPI flume was also set to run at absolute top speed, just reaching $0.22 \mathrm{~m} \mathrm{~s}^{-1}$. Similarly, these two data sets stand out immediately with regard to the levels of turbulence, and both these data sets also show a rather high level in covariance between the $v$ and $w$ flow components.

The initial assumption that for all the flume facilities measurements taken at $0.05 \mathrm{~m}$ above the bed and at $20 \%$ of the water depth would be within the boundary layer also turned out to be violated. Both the annular flumes (SOC and PML) as well as one of the straight ones (GML), had relatively thin boundary layers at both velocities. This has obvious consequences for estimates of Reynolds Stress, $\rho \overline{u^{\prime} w^{\prime}}$, which denotes the flux of momentum in the vertical direction. Momentum transport will take place from high velocity areas towards low velocity areas, i.e. in the benthic boundary layer $\rho \overline{u^{\prime} w^{\prime}}$ should result in a negative value (Massel, 1999; Tritton, 1988). PML therefore supplied a time series dataset recorded at a height of $0.005 \mathrm{~m}$ above the bed. This does indeed yield negative values for $\rho \overline{u^{\prime} w^{\prime}}$, but since this is so close to the solid boundary, this data set is not directly comparable to the other ones. Particularly when we view the spectral density graphs, we can see that it looks very flat, and that the slope in the inertial sub-range deviates considerably from Kolmogorov's $-5 / 3$ law. So close to a solid surface the vortices and eddies in the water are presumably directly physically constrained in their size and fully developed turbulence cannot be expected.

It should be noted that since Reynolds stress is sensitive to direction, this measurement is also very sensitive to the proper alignment of the ADV. In all ADV measurements the $\bar{v}$ component was extremely small compared to the $\bar{u}$ component. The field measurements were carried out in flow with a very predictable direction. Therefore this is not an issue here. However in other situations it may be necessary to rotate the flow field in such a way that the main flow direction is along the x-axis before any calculation of Reynolds stress.

One of the major problems with this large-scale comparison of flume facilities is that it was not possible to carry out all the flow measurements with the same type of equipment. For the comparison of the velocity profiles, this problem is probably limited, however for comparison of levels of turbulence this does pose a serious problem. Assuming all the ADV measurements have been carried out correctly (right seeding densities, velocity range settings 
and correct alignment of the ADV) these should be directly comparable, both for levels of turbulence intensity as for estimates of TKE and Reynolds stress. Particularly Reynolds stress estimates are highly influenced by the ADV alignment. Since most methods other than ADV also give some estimate of variability of velocity components, we calculated turbulence intensities for these datasets as well. The TI estimates are based on the standard deviation of the velocity measurements and these estimates are influenced by the noise in the measurement device. For ADV, LDA, ultrasonic devices and any other Doppler based backscatter system the main source of error is the so-called Doppler noise (Nikora \& Goring, 1999). The main contributor to this Doppler noise is the residence time of particles in the measuring volume. Therefore the contribution of the Doppler noise to the total velocity fluctuations measured will differ between devices. Provided the noise level of the device is small with regard to the velocity fluctuations, the effect of the type of device should be limited. This is usually the case in turbulent situations such as boundary layers. Generally there is very good agreement in estimates of e.g. Reynolds stress between LDA and ADV (Lohrmann et al., 1995).

\section{Bottom roughness}

Although the bottom in some of the flumes consisted of smooth PVC or fibreglass, whilst in other flumes it consisted of sediment, there was no clear relationship between the bottom material and the estimate of the roughness length, $\mathrm{z}_{0}$. The way in which roughness influences the boundary layer depends principally upon the size and spacing of the roughness elements relative to the length scales of motion of the overlying fluid (Dade et al., 2001; Grant \& Madsen, 1986). In other words, it does not depend directly upon the size of the sediment grains per se, but on the ratio between grain size $\left(\mathrm{k}_{\mathrm{s}}\right)$ on the one hand and the viscous length scale, $\left(v / u_{*}\right)$ on the other. If $\mathrm{k}_{\mathrm{s}}$ is of equal size or smaller than the viscous length scale, the roughness elements are effectively submerged within the viscous sub-layer and the bed is considered to be hydrodynamically smooth. If $\mathrm{k}_{\mathrm{s}}$ is more than 10 times larger than $\mathrm{v} / \mathrm{u}_{*}$, the bed is hydrodynamically rough, and $\mathrm{k}_{\mathrm{s}} / \mathrm{z}_{0}$ equals about 30 (Dade et al., 2001). Therefore, as long as in the flumes with a sediment bottom, the sediment was properly smoothed out, without mounds or depressions, the flow will have been hydrodynamically smooth and no consistent difference between smooth plastic and sandy surfaces was to be expected. 


\section{Scaling considerations}

A critical question when studying biological processes in boundary layer flow is how to scale flow conditions in the flume to allow valid conclusions about field situations. The choice of scaling for boundary layer characteristics depends upon the problem under study. Although almost every study calls for a unique set of considerations, it is possible to identify some classes of problems with specific requirements in terms of scaling to allow relevant translation to field conditions. Below follows a discussion of the most common scaling considerations. However, this list is far from exhaustive, and it is important to realise that it is generally not possible to simultaneously scale all hydrodynamics conditions in a flume.

\section{Flume turbulence}

Inspection of the turbulence intensities and the autocorrelation spectra shows that the flow regime in all flumes was turbulent, even for the slower free-stream velocity. The transition from laminar to turbulent boundary layer flow can be predicted from the local Reynolds number $\left(\operatorname{Re}_{\mathrm{x}}\right)$. For an ideal channel with a smooth bed, transition to turbulent flow is expected when $\operatorname{Re}_{\mathrm{x}}$ exceeds $\sim 500000$. However, deviations from a smooth bed can significantly reduce this critical $\mathrm{Re}_{\mathrm{x}}$. In fact, $\mathrm{Re}_{\mathrm{x}}$ for many of the flumes was far below this critical value. The shorter flumes (CREMA, ROSTOCK, KUCORPI and LOB) have a $\operatorname{Re}_{\mathrm{x}}$ of $\sim 100000$ for the slower test flow. In spite of this low $\operatorname{Re}_{\mathrm{x}}$ there was no evidence that turbulence was less developed than for the longer flumes with higher $\mathrm{Re}_{\mathrm{x}}$. A partial explanation for the unexpectedly well-developed turbulence is that slight roughness elements in the flow channel promote initial turbulent structures. More important is that the flow is probably already turbulent when entering the flow channel. In the straight, as well as in the racetrack flumes, the water passes through propulsion generators (propellers, paddles etc.) and is forced to follow bending pipes or vanes before entering the straight working section. Nearly all flumes with straight test sections have some device to collimate the flow at the entrance; this should act as a low-band filter and cut large-scale eddies, whilst small-scale eddies are free to pass. Thus the flow already carries TKE when entering the working section and the development of a fully turbulent boundary layer is faster than predicted by the $\operatorname{Re}_{\mathrm{x}}$. The conclusion is that even rather short flumes can produce turbulent boundary layers for relatively slow flows. This also implies that if laminar flow is desired, much care must be taken to dissipate all TKE in the water column prior to entering the working section. 
A wider question in relation to the development of turbulence in flumes is how well these turbulence levels correspond to relevant field situations; when does this matter and how should turbulence be scaled from field to flume conditions? The data series available from field boundary layers indicate that TKE levels may be considerably lower in flumes than in the field at the same velocity. It is of course important to realise that in the field, particularly in shallow areas, turbulence is not just generated at the bottom. Wind-driven circulation and and breaking surface waves will generate turbulent energy that is subsequently transported down. In addition to this, flow in the field is seldom very steady and changes in velocity and direction, e.g. caused by waves are an additional source of turbulence in the boundary layer. However, also the necessary size constrictions of a flume channel will cause artefacts. Flumes will inevitably have a lack of large-scale eddies. More TKE can be introduced at smaller scales using grids or rotating devices upstream of the working section. In the NIOO flume the introduction of a grid (holes $\varnothing 5 \mathrm{~cm}$ ) increased the TI by $35 \%$ at $0.25 \mathrm{~m} \mathrm{~s}^{-1}$ (NIOO, unpublished data). The importance of suitable scaling of turbulent parameters depends upon the research problem addressed. For many biomechanical studies focused upon drag and lift forces the accurate scaling of turbulence may be less important. However, as pointed out by e.g. Sanford (1997), studies that involve mixing of solutes or particles in the boundary layer may depend critically upon the accurate scaling of turbulence. This also applies to resuspension of sediment (van der Ham et al., 2001) as well as bed-load transport of organisms, e.g. benthic prostists (Shimeta \& Sisson, 1999), and settling larvae (McNair et al., 1997). Straight and racetrack flumes generally seem to offer the best solution to experimental studies of boundary layer mixing (Sanford, 1997). Essentially, the shear velocity can be used to scale the turbulent mixing within the boundary layer (Nowell \& Jumars, 1984). The lack of certain turbulent scales in flumes implies that scaling of the shear velocity requires a higher free-stream velocity in the flume than in the target field situation. This is also supported by the comparison of shear velocities and TI between flumes and field data sets in the present study. A useful non-dimensional scaling parameter to predict mixing of non-cohesive particles is the Rouse number:

$$
R o=\frac{w_{s}}{u_{*} \kappa}
$$

where $\mathrm{w}_{\mathrm{s}}$ is the particle settling velocity. This number is also similar to the vertical Péclet number, the ratio between advection and turbulent mixing $\left(\mathrm{Ro}=6 \mathrm{Pe}_{\mathrm{v}}\right)$. It is important to bear in mind that this applies only to turbulent mixing in steady flows. In oscillatory flows driven 
by wave motion the mixing and transport at the bed may increase by orders of magnitude (Denny, 1988). When wave action comes into the equation, the Froude number, i.e. the ratio between inertial and gravitational forces, should be matched:

$$
F r=\frac{U}{\sqrt{g L}}
$$

where $\mathrm{U}$ indicates the flow velocity, $\mathrm{g}$ the gravitational acceleration and $\mathrm{L}$ a relevant length scale, often the water depth. However, simultaneously scaling of Reynolds number and Froude number is often impossible in practice. Generally, when waves are considered to have an important impact on a particular process, Froude number scaling is maintained and Reynolds number scaling is relaxed (Tritton, 1988).

\section{Drag and lift}

The Reynolds number is used to scale flume flow situations to assess drag and lift forces on a solid body, e.g. an organism (e.g. Vogel, 1994). Different characteristic length scales are used depending on the flow problem, but commonly the stream-wise maximum body dimension is used. If the experiment requires live organisms, it will not be possible to manipulate fluid density or viscosity, and this implies that local velocity in the flume has to correspond to field flow speeds. In the boundary layer, local velocity decreases towards the bed. Consequently, the total drag force acting on an organism in the boundary layer has to be integrated over the body, and will depend upon the vertical velocity gradient.

\section{Bed shear stress}

Bed shear stress is a measure of the frictional forces resulting from the interaction of fluid moving past the bottom (Ackerman \& Hoover, 2001). It is a direct result of the tendency of the fluid to resist deformation, i.e. the viscosity of the fluid. The bed shear stress reflects the momentum flux from the fluid to the bed (Vogel, 1994; Dade et al., 2001). In turbulent boundary layers, bed shear stress $\left(\tau_{0}\right)$ scales with shear velocity in the relationship

$$
\tau_{0}=\rho u_{*}^{2}
$$

This relation assumes a fully turbulent boundary layer and a logarithmic velocity gradient. However, since bed shear stress is a bed surface phenomenon it is possible to calibrate it to a range of other flow characteristics, e.g. free-stream velocity, and an appropriate scaling of the boundary layer flow can be relaxed. In this respect, the annular flumes included in the present 
study can be used to produce specified bed shear stresses despite strong deviations from field boundary layer velocity gradients. Bed shear stress is often used to predict bed-load transport and resuspension of sediment particles. Although shear stress is one important stress term affecting the probability of sediment transport, other terms may be equally or more important; most notably, the drag and lift forces proportional to the square of the local downstream velocity (Clifford et al., 1991).

\section{Boundary layer thickness}

The thickness $(\delta)$ of a turbulent boundary layer grows with free-stream velocity $\left(\mathrm{u}_{\infty}\right)$ and the downstream length $(\mathrm{x})$ as:

$$
\delta=0.376 x \sqrt[5]{\frac{v}{x u_{\infty}}}
$$

or

$$
\frac{\delta}{x}=0.376 \operatorname{Re}_{x}^{-1 / 5}
$$

This implies that in each flume the boundary layer should be $27 \%$ thinner at the higher flow velocity. For some of the flumes the actual boundary layer thickness could not be established because either the boundary layer extended right up to the surface, or the measurements did not extend outside the boundary layer. However, for those flumes where boundary layer thickness could be established, we were unable to find any consistent differences in thickness between the two velocities. The autocorrelation spectra showed that in all flumes turbulence was developed fully at the point of measurement. However, $\mathrm{Re}_{\delta}$ at the low velocity in many of the flumes was close to 3000, which is close to the critical channel Reynolds number $\left(\mathrm{Re}_{\mathrm{c}}\right)$, where flow is expected to be fully turbulent (Nowell \& Jumars 1987). In some of the flumes turbulence at the low flow velocity may not have been fully developed in the front part of the test section.

If a flume study considers organisms living normally within the boundary layer, the flume should be sufficiently long to allow the development of a boundary layer thicker than the organism. This scaling may be of particular importance for studies of advection-diffusion processes, such as encounter rate with particles, release of gametes, or the perception of chemical cues. This is certainly a concern for the annular flumes, where the boundary layer had a thickness of less than $1 \mathrm{~cm}$. In the present study, flumes with a straight section 
produced boundary layers between 3 and $15 \mathrm{~cm}$ thick, indicating that also for these facilities there may be constraints for working with larger organisms, e.g. macroalgae and seagrasses.

\section{Viscous sub-layer}

In hydraulically smooth flow, a viscous sub-layer exists at the bed. In this layer mixing of solutes and neutrally buoyant particles depends mainly on viscous processes. The presence and the thickness of this viscous sub-layer may be important for processes like exchange rates across the sediment-water interface (Gundersen \& Jørgensen, 1990; Dade, 1993), spread and residence of chemical cues, and potential for behavioural responses of microbial life (Jonsson \& Johansson, 1997). The roughness Reynolds number $\left(\mathrm{Re}_{*}\right)$ predicts that the flow is hydraulically smooth, with a viscous sub-layer present when $\operatorname{Re} *<10$. In hydraulically smooth flows, the thickness of the viscous sub-layer scales with shear velocity as $11.5 \mathrm{v} / \mathrm{u} *$. Note that in hydraulically rough flows ( $\operatorname{Re}_{*}>100$ ), there may be also a molecular diffusive layer in the still layer among roughness elements if the flow is completely skimming (Denny, 1988). In the present study, all flume flows were hydraulically smooth with expected viscous sub-layers of 1-7 mm and 0.7-2 $\mathrm{mm}$ for the free-stream velocities 0.05 and $0.25 \mathrm{~m} \mathrm{~s}^{-1}$, respectively.

\section{Consequences of flume design on boundary layer properties}

\section{Width to depth ratio}

Nowell and Jumars (1987) recommended that, for reproducing biologically relevant boundary layers, flume width should be greater than flume depth by at least a factor of 5 . All flume tanks involved in this study had a width to depth ratio of 4 or less, and therefore violated this rule-of-thumb. However, we did not observe a very clear relationship between the $r^{2}$ of the regression coefficient of the boundary layers and the width (W) to depth (H) ratio. The very narrow flumes appeared to produce slightly lower $r^{2}$ values, but these flumes were the annular flumes, that seemed to produce quite a thin boundary layer in the first place. We hypothesise that, rather than the width to depth ratio, the ratio between the flume width and the wall boundary layer thickness is probably more important. For many experiments it will be important to make sure that measurements are taken well away from the wall boundary layers. These will be of the same order of magnitude as the bottom boundary layer $(\delta)$. We therefore propose an alternative rule of thumb: the width of the flume should be larger than 
$2 \delta+\mathrm{k}_{\mathrm{y}}$, where $\mathrm{k}_{\mathrm{y}}$ is the relevant length scale of objects or processes in the horizontal direction, perpendicular to the main flow.

\section{Straight versus curved test sections}

Straight flumes and racetrack designs seemed to produce boundary layers with a well defined log-profile, in many respects similar to boundary layers observed in the field. The annular flumes with a curved test section, however, showed a different picture. The main advantage of annular flumes is that they lack an entrance to the test section, and that therefore the test section is of infinite length. Boundary layer development over a flat surface depends (theoretically) on the distance to the "entrance” (Schlichting, 1979; Vogel, 1994) flumes with an infinitely long test section should always have a fully developed boundary layer. The curved channel, however, may cause secondary flows to develop, and the fluid may end up "spiralling" through the channel. This is due to the centrifugal force causing the water level to be higher on the outer curve of the channel. This in turn causes a pressure difference on the bottom, and consequently a radial flow. The high level of covariance between the $v^{\prime}$ and $w$ ' velocity components is indicative of such an effect. Annular flumes are used a lot in sedimentology, and some of the modern versions are provided with counter-rotating bottoms or channels to reduce these secondary flows (Yang et al., 2000). However, even in such flumes, secondary flows are not avoided altogether (Hunt, 2004) and for certain applications, particularly in biology, such engineering features may be impractical. Annular flumes have been deployed in situ, on intertidal mudflats to study the interaction of sediments with benthic fauna and flora (Droppo \& Amos, 2001; Widdows et al., 1998). Being able to use this type of flume on undisturbed sediment in the field is obviously a major advantage.

Although the fact that these set-ups produce boundary layers that are different in structure from those observed in the field, they still yield very relevant data, provided the hydrodynamic characteristics are taken into account. Annular flumes such as these are particularly useful for experiments on exchange processes at the sediment-water interface, such as experiments on erosion thresholds and erosion rates (Thompson \& Amos, 2004), provided that parameters such as shear velocity or shear stress are accurately assessed. One has to be cautious about linking sedimentation and erosion rates merely to absolute freestream velocity. In flumes with such a thin boundary layer the shear stress associated with a certain velocity will be very different from situations with a thicker logarithmic layer.

For certain applications the hydrodynamic artefacts produced by these flumes will be a serious constraint. Transport rates of particulate material (sediment, algae, settling larvae) are 
influenced by the shape of the boundary layer. Although a flume will never reproduce completely the field situation, it is necessary for such studies to have a flume that will reproduce a boundary layer with an identifiable log-layer. The boundary layers in the annular flumes in this study are so thin that no "normal" log layer exists. The boundary layer has the thickness of what would normally be the viscous sub-layer. For such studies the annular flumes without devices to counteract secondary flows are less appropriate. Annular flumes with counter rotating channels appear to have considerably thicker boundary layers. Hunt (2004) reports a well-defined log-layer of $3.9 \mathrm{~cm}$ in an annular flume at Rutgers University.

On the other hand there is often also a price to pay for the more realistic hydrodynamical regime in straight and racetrack flumes. Devices such as collimators and turning vanes to reduce turbulence and secondary flows tend to have a fairly large surface area to which suspended material can adhere. Straight and racetrack flumes with a relatively small test section compared to the total surface area of the flume, can often have a very large particle retention rate. Certainly for experiments on filtration rates of benthic filter feeders or sedimentation and erosion experiments this can be a serious source of measurement error. For such experiments it is very important to do a series of blank experiments to assess the importance of particle “consumption” by the flume itself. In annular flumes this issue is of far less importance.

\section{Lab versus field facilities}

Laboratory flumes in which flow, light, temperature and other conditions are completely controlled are excellent for many fundamental research questions, particularly in biology. However, there are always major problems in translating the lab results to the field. Processes that appear to be important in the lab may be masked completely in the field because other variables have much greater influence. Field flumes, such as the AWI facilities are a very useful intermediate between the lab and the field. Inevitably, these structures also have a number of design constraints and limitations. The in-flow funnels of the AWI flumes are large relative to the short test section. After either a constriction or an expansion in a pipe or a channel, it takes a certain distance for a stable profile to develop (Tritton, 1988). The same applies to a change in direction in a channel, as for instance in the control channels of the AWI flume. Secondary flows may occur, especially at the start of the test section, which may in turn influence levels of turbulence. Engineers use as a rule of thumb for pipe flow that a downstream length of at least several pipe diameters is needed for the flow to stabilise. However, provided one takes these artefacts into account when interpreting the data, these 
field constructions can be very valuable. They allow experimentation under more or less natural circumstances and on a spatial scale that is often difficult to realise in an indoor laboratory. Every flume facility is a compromise between what is hydrodynamically ideal and what is practically feasible. Field flumes are no exception.

\section{Flume and field comparisons}

The constant conditions in laboratory flumes allow an unrestricted number and duration of successive measurements. In the field and in the field flumes, conditions are constantly changing. Successive points of flow measurements may not always be lumped together and considered to be one profile, if over the course of these measurements flow velocity, flow direction and/or water depth has changed significantly. For the field flume data series we selected a dataset from each of the different channels, where the velocity profiles were measured within 9 minutes, and during which the water level did not change over more than $6 \mathrm{~cm}$. However, in one of the runs this still meant an increase in water depth of $25 \%$. Conditions during the three datasets collected in the field were much more stable. In the Saltö channel in Sweden, where two profiles were collected, conditions are naturally quite stable. With profiles collected in the Oosterschelde, special care was taken to ensure that changes in flow velocity were minimal. Water depth changed less than $3 \%$ over the duration of the collection of the profile. These two field profiles compare quite well with most of the straight flume profiles. That does not mean that we can take these profiles as "representative for the field”, or that the profiles from the AWI flume are an artefact. We have to bear in mind that the boundary layer in the field may deviate considerably from the logarithmic profile because of unsteady or oscillatory flow, particularly in shallow ecosystems with a lot of wind stress and changing tides. For many biological processes occurring in such an environment, a nicely predictable logarithmic boundary layer, with a constant shear stress, should in fact be considered to be an artefact, just like any other anomaly introduced by flume design. Being able to measure a full velocity profile within a very short time window is therefore particularly important. Either a large array of similar measuring devices (such as ADVs or hot-film probes) is required, or a device is needed that can derive nearly instantaneous profiles for the whole water column. Acoustic Doppler Current Profilers (ADCP) are very suitable. These devices cannot only be used to measure velocity profiles, but techniques have also been developed to derive turbulence characteristics from these data (Rippeth et al., 2002). However, these devices are not suitable for measurements very close to the sediment surface, the area most relevant for benthic organisms. Upward looking systems have a large 
blank zone close to the bed. Downward looking systems that do get close to the bed, still average over a fairly large depth range (often around $30 \mathrm{~cm}$, depending on the configuration). Although recently some manufacturers have developed mini ADCPs for work in very shallow water that reduce this volume considerably. Relatively close to the bed, parameters such as shear velocity can be derived probably from a limited number of Reynolds stress measurements with ADVs. Combining techniques such as ADV and ADCP measurements looks like a promising option.

\section{Concluding remarks}

Flumes for biological research have specific requirements, related to working with living organisms. The requirement to compromise between optimising the physics and optimising the facilities for marine and freshwater plants and animals is inherent to this field of research. This comparison of the 12 different biological flumes leads to some encouraging conclusions. With the exception of the annular flumes, all flumes produced relatively well-defined logarithmic boundary layers. The standard deviation of the shear velocities for all straight and racetrack flumes was less than $25 \%$ of the mean, despite the great diversity of size and design. In particular, the ratio between water depth and flume width had a minor effect on the estimate of shear velocity. Despite the fact that some facilities were not very large, the flow in all the flumes was fully turbulent and shear velocities were in the same order of magnitude as field data, although TKE tended to be lower in the flumes at high velocities. In summary, most of the tested straight and racetrack flumes should be useful for a range of biological flow-related problems, provided that the dimensions of the flume tank are appropriate for the scales of the hydrodynamic processes under consideration. The flow profile in the annular flumes deviated from that in the other designs. This is an important issue to bear in mind when interpreting the results from these devices. The use of annular flumes should be restricted to research questions where the actual velocity profile in the water column is not critical. The field flumes also produced some hydrodynamic artefacts. Although these obviously have to be considered when discussing the results, none of the laboratory set-ups can mimic exactly the different variables of the field situation in every respect.

\section{Acknowledgements}

We would like to acknowledge the comments and contributions of various BioFlow members who are not on the author's list. We also thank two anonymous referees whose comments 
greatly improved the manuscript. Finally we gratefully acknowledge the financing by the EU of BioFlow.

\section{Reference List}

Ackerman JD. (1997) Submarine pollination in the marine angiosperm Zostera marina (Zosteraceae). 2. Pollen transport in flow fields and capture by stigmas. American Journal of Botany 84(8): 1110-1119.

André C, Jonsson PR and Lindegarth M. (1993) Predation on settling bivalve larvae by benthic suspension feeders: the role of hydrodynamics and behaviour. Mar Ecol Prog Ser 97: 183-192.

Berntsson KM, Jonsson PR, Lejhall M and Gatenholm P. (2001) Analysis of behavioural rejection of micro-textured surfaces and implications for recruitment by the barnacle Balanus improvisus. J Exp Mar Biol Ecol 251: 59-83.

Blanchard GF, Sauriau P-G, Cariou-Le Gall V, Gouleau D, Garet M-J and Olivier F. (1997) Kinetics of tidal resuspension of microbiota: testing the effects of sediment cohesiveness and bioturbation using flume experiments. Mar Ecol Prog Ser 151: 1725.

Boudreau BP and Jørgensen BB. (2001) The Benthic Boundary Layer. Boudreau, B. P. and Jørgensen, B. B. Oxford, Oxford University Press.

Butman CA, Fréchette M, Geyer WR and Starczak VR. (1994) Flume experiments on food supply to the blue mussel Mytilus edulis L. as a function of boundary layer flow. Limnol Oceanogr 39(7): 1755-1768.

Clifford NJ, McClatchey J and French JR. (1991) Measurements of turbulence in the benthic boundary-layer over a gravel bed and comparison between acoustic measurements and predictions of the bedload transport of marine gravels. Sedimentology 38(1): 161166.

Dade WB. (1993) Near-bed turbulence and hydrodynamic control of diffusional mass transfer at the sea floor. Limnol Oceanogr 38(1): 52-69. 
Dade WB, Hogg AJ and Boudreau BP. (2001) Physics of flow above the sediment-water interface. Boudreau, B. P. and Jørgensen, B. B. The Benthic Boundary Layer. (2): 437. Oxford, Oxford University Press.

Denny MW. (1988) Biology and the Mechanics of the Wave-Swept Environment. Princeton, Princeton University Press.

Denny MW, Daniel TL and Koehl MAR. (1985) Mechanical limits to size in wave-swept organisms. Ecological Monographs 55(1): 69-102.

Dolmer P and Frandsen RP. (2002) Evaluation of the Danish mussel fishery: suggestions for an ecosystem management approach. Helgoland Marine Research 56(1): 13-20.

Droppo IG and Amos CL. (2001) Structure, stability, and transformation of contaminated lacustrine surface fine-grained laminae. J Sed Res 71(5): 717-726.

Eckman JE and Duggins DO. (1998) Larval settlement in turbulent pipe flows. J Mar Res 56(6): 1285-1312.

Fréchette M, Butman CA and Geyer WR. (1989) The importance of boundary-layer flows in supplying phytoplankton to the benthic suspension feeder, Mytilus edulis L. Limnol Oceanogr 34(1): 19-36.

Gambi MC, Nowell ARM and Jumars PA. (1990) Flume observations on flow dynamics in Zostera marina (eelgrass) beds. Mar Ecol Prog Ser 61: 159-169.

Goring DG and Nikora VI. (2002) Despiking acoustic Doppler velocimeter data. J Hydrol Eng 128(1): 117-126.

Granata TC, Serra T, Colomer J, Casamitjana X, Duarte CM and Gacia E. (2001) Flow and particle distributions in a nearshore seagrass meadow before and after a storm. Mar Ecol Prog Ser 218: 95-106.

Grant WD and Madsen OS. (1986) The continental-shelf bottom boundary layer. Ann Rev Fluid Mech 18: 265-305.

Gundersen JK and Jørgensen BB. (1990) Microstructure of diffusive boundary-layers and the oxygen- uptake of the sea-floor. Nature 345(6276): 604-607. 
Havenhand JN and Svane I. (1991) Roles of hydrodynamics and larval behavior in determining spatial aggregation in the tunicate Ciona intestinalis. Mar Ecol Prog Ser 68(3): 271-276.

Hawkins AJS, Fang JG, Pascoe PL, Zhang JH, Zhang XL and Zhu MY. (2001) Modelling short-term responsive adjustments in particle clearance rate among bivalve suspension-feeders: separate unimodal effects of seston volume and composition in the scallop Chlamys farreri. J Exp Mar Biol Ecol 262(1): 61-73.

Herman PMJ, Middelburg JJ and Heip CHR. (2001) Benthic community structure and sediment processes on an intertidal flat: results from the ECOFLAT project. Cont Shelf Res 21(18-19): 2055-2071.

Hunt HL. (2004) Effects of epibenthic predators in flow: transport and mortality of juveniles of the soft shell clam Mya arenaria. Marine Ecology-Progress Series 279: 151-160.

Jonsson PR and Johansson M. (1997) Swimming behaviour, patch exploitation and dispersal capacity of a marine benthic ciliate in flume flow. J Exp Mar Biol Ecol 215: 135-153.

Kim SC, Friedrichs CT, Maa JPY and Wright LD. (2000) Estimating bottom stress in tidal boundary layer from Acoustic Doppler Velocimeter data. J Hydrol Eng 126(6): 399406.

Leonard GH, Levine JM, Schmidt PR and Bertness MD. (1998) Flow driven variation in intertidal community structure in a Maine Estuary. Ecology 79(4): 1395-1411.

Lohrmann A, Cabrera R, Gelfenbaum G and Haines J. (1995) Direct measurements of Reynolds stress with an acoustic Doppler Velocimeter. Proceedings of the IEEE fifth working conference on current measurements : 205-210.

Massel SR. (1999) Fluid Mechanics for Marine Ecologists. Berlin, Springer.

McNair JN, Newbold JD and Hart DD. (1997) Turbulent transport of suspended particles and dispersing benthic organisms: How long to hit bottom? J Theor Biol 188(1): 29-52.

Möller I, Spencer T, French JR, Leggett DJ and Dixon M. (1999) Wave transformation over salt marshes: A field and numerical modelling study from north Norfolk, England. Estuarine Coastal and Shelf Science 49(3): 411-426. 
Nepf HM, Mugnier CG and Zavistoski RA. (1997) The effects of vegetation on longitudinal dispersion. Estuarine Coastal and Shelf Science 44(6): 675-684.

Nikora VI and Goring DG. (1999) ADV measurements of turbulence: can we improve their interpretation? J Hydrol Eng 124: 630-634.

Nikora VI, Goring DG and Biggs BJF. (1997) On stream periphyton - turbulence interactions. N Z J Mar Freshwater Res 31: 435-448.

Nowell ARM and Jumars PA. (1987) Flumes: Theoretical and experimental considerations for simulation of benthic environments. Oceanograph Mar Biol Ann Rev 25: 91-112.

Nowell ARM and Jumars PA. (1984) Flow environments of aquatic benthos. Ann Rev Ecol Sys 15: 303-328.

Paterson DM, Tolhurst TJ, Kelly JA, Honeywill C, de Deckere EMGT, Huet V, Shayler SA, Black KS, de Brouwer J and Davidson I. (2000) Variations in sediment properties, Skeffling mudfalt, Humber Estuary, UK. Cont Shelf Res 20: 1373-1396.

Riisgård HU and Larsen PS. (1995) Filter-feeding in marine macro-invertebrates: pump characteristics, modelling and energy cost. Biological Reviews 70: 67-106.

Rippeth TP, Williams E and Simpson JH. (2002) Reynolds stress and turbulent energy production in a tidal channel. J Phys Oceanogr 32(4): 1242-1251.

Sanford LP. (1997) Turbulent mixing in experimental ecosystem studies. Mar Ecol Prog Ser 161: 265-293.

Schlichting H. (1979) Boundary Layer Theory. 7. New York, McGraw-Hill.

Shimeta J and Sisson JD. (1999) Taxon-specific tidal resuspension of protists into the subtidal benthic boundary layer of a coastal embayment. Mar Ecol Prog Ser 177: 5162.

Shimeta J, Starczak VR, Ashiru OM and Zimmer CA. (2001) Influences of benthic boundarylayer flow on feeding rates of ciliates and flagellates at the sediment-water interface. Limnol Oceanogr 46(7): 1709-1719. 
Tennekes H and Lumley JL. (1999) A first course in turbulence. 17. Cambridge, Massachusetts.

Thompson CEL and Amos CL. (2004) Effect of sand movement on a cohesive substrate. Journal of Hydraulic Engineering-Asce 130(11): 1123-1125.

Tolhurst TJ, Riethmüller R and Paterson DM. (2000) In situ versus laboratory analysis of sediment stability from intertidal mudflats. Cont Shelf Res 20: 1317-1334.

Tritton DJ. (1988) Physical Fluid Dynamics. 2. New York, Oxford University Press.

van der Ham R, Fontijn HL, Kranenburg C and Winterwerp JC. (2001) Turbulent exchange of fine sediments in a tidal channel in the Ems/Dollard estuary. Part I: Turbulence measurements. Cont Shelf Res 21(15): 1605-1628.

Vogel S. (1994) Life in moving fluids. Princeton, New Jersey, Princeton University Press.

Widdows J, Brinsley MD, Salkeld PN and Elliott M. (1998) Use of annular flumes to determine the influence of current velocity and bivalves on material flux at the sediment-water interface. Estuaries 21(4A): 552-559.

Widdows J, Brinsley MD, Salkeld PN and Lucas CH. (2000) Influence of biota on spatial and temporal variation in sediment erodability and material flux on a tidal flat (Westerschelde, The Netherlands). Mar Ecol Prog Ser 194: 23-37.

Yang ZQ, Baptista A and Darland J. (2000) Numerical modeling of flow characteristics in a rotating annular flume. Dynamics of Atmospheres and Oceans 31(1-4): 271-294. 
Table 1 notation

\begin{tabular}{|c|c|c|}
\hline $\mathrm{Fr}$ & - & Froude number \\
\hline $\mathrm{H}$ & $\mathrm{m}$ & height of the water column \\
\hline$\kappa$ & - & Von Karman constant (approx 0.4) \\
\hline $\mathrm{k}$ & $m^{-1}$ & wave number \\
\hline $\mathrm{k}_{\mathrm{s}}$ & $\mathrm{m}$ & sediment grain size \\
\hline$v$ & $m^{2} s^{-1}$ & kinematic viscosity \\
\hline $\mathrm{Pe}$ & - & Péclet number (ratio between advection and turbulent mixing) \\
\hline$\rho$ & $\mathrm{kg} \mathrm{m}^{-3}$ & density \\
\hline $\operatorname{Re}$ & - & Reynolds number (ratio between inertial and viscous forces) \\
\hline $\operatorname{Re}_{c}$ & - & channel Reynolds number \\
\hline $\operatorname{Re}_{\mathrm{x}}$ & - & local Reynolds number \\
\hline $\mathrm{Re}_{*}$ & - & roughness Reynolds number \\
\hline Ro & - & Rouse number (ratio between vertical velocity and shear velocity) \\
\hline$-\rho \overline{u^{\prime} w^{\prime}}$ & $\operatorname{Pa}\left(\mathrm{kg} \mathrm{m}^{-1} \mathrm{~s}^{-2}\right)$ & Reynolds stress \\
\hline$\tau_{0}$ & $\mathrm{~Pa}\left(\mathrm{~kg} \mathrm{~m}^{-1} \mathrm{~s}^{-2}\right)$ & bottom shear stress \\
\hline TI & $\%$ & turbulence intensity \\
\hline TKE & $m^{2} s^{-2}$ & turbulent kinetic energy \\
\hline$u v$ and $w$ & $\mathrm{~m} \mathrm{~s}^{-1}$ & velocity components in $\mathrm{x}, \mathrm{y}$ and $\mathrm{z}$ \\
\hline $\mathrm{u}_{*}$ & $\mathrm{~m} \mathrm{~s}^{-1}$ & shear velocity \\
\hline$u^{\prime}, v^{\prime}$ and $w^{\prime}$ & $\mathrm{m} \mathrm{s}^{-1}$ & fluctuating velocity component in $\mathrm{x}, \mathrm{y}$ and $\mathrm{z}$ \\
\hline $\mathrm{U}_{\infty}$ & $\mathrm{m} \mathrm{s}^{-1}$ & free-stream velocity \\
\hline $\mathrm{u}^{+}$ & - & dimensionless velocity scale $\left(\mathrm{u} / \mathrm{u}^{*}\right)$ \\
\hline $\mathrm{z}$ & $\mathrm{m}$ & height above bed \\
\hline $\mathrm{z}_{0}$ & $\mathrm{~m}$ & roughness length \\
\hline $\mathrm{z}^{+}$ & - & dimensionless length scale $\left(\mathrm{z} \mathrm{u}_{*} / \mathrm{v}\right)$ \\
\hline
\end{tabular}


Table 2 Flume descriptions

\begin{tabular}{|c|c|c|c|c|c|c|c|c|c|c|c|}
\hline Institute & Flume design & Test section & Bottom material & $\begin{array}{c}\text { Flume length } \\
\text { (m) }\end{array}$ & $\begin{array}{c}\text { Flume width } \\
\text { (m) }\end{array}$ & $\begin{array}{c}\text { Water depth } \\
(\mathrm{m})\end{array}$ & $\begin{array}{c}\text { Ratio } \\
\text { width/depth }\end{array}$ & $\begin{array}{c}\text { Flume } \\
\text { volume }\left(\mathrm{m}^{3}\right)\end{array}$ & $\begin{array}{c}\text { Temperature } \\
\left({ }^{\circ} \mathrm{C}\right)\end{array}$ & Salinity (\%) & Flow measurement device ${ }^{*}$ \\
\hline GML & straight & straight & steel & 7.0 & 0.30 & 0.24 & 1.3 & 2.60 & 20.0 & 30.0 & ADV \\
\hline TMBL & straight & straight & plexiglass & 5.5 & 0.50 & 0.13 & 4.0 & 1.50 & 16.0 & 32.0 & ADV $10 \mathrm{MHz}$, hot-film probe \\
\hline MPI-MM & straight & straight & sand, $200 \mu \mathrm{m}$ & 5.4 & 0.48 & 0.19 & 2.5 & 2.00 & 18.0 & 31.0 & LDA, 2D \\
\hline CREMA & straight & straight & pvc & 3.0 & 0.40 & 0.15 & 2.7 & 1.16 & 15.0 & 31.0 & Ultra sonic, 2-way 16 MHz \\
\hline ROSTOCK & straight & straight & sand, $200 \mu \mathrm{m}$ & 3.0 & 0.40 & 0.20 & 2.0 & 0.36 & 15.7 & 30.0 & ADV $10 \mathrm{MHz}$ \\
\hline KUCORPI & straight & straight & glass & 2.3 & 0.48 & 0.14 & 3.4 & 0.30 & 18.0 & 0.0 & ADV $10 \mathrm{MHz}$ \\
\hline LOB & straight & straight & pvc & 1.7 & 0.40 & 0.10 & 4.0 & 0.30 & 25.0 & 37.5 & LDA, 2D \\
\hline $\mathrm{NIOO}$ & race track & straight & smooth fibre glass & 9.0 & 0.60 & 0.39 & 1.5 & 10.00 & 15.0 & 26.0 & ADV $10 \mathrm{MHz}$ \\
\hline MNHN & race track & straight & plexiglass & 6.0 & 0.50 & 0.15 & 3.3 & 1.00 & 19.5 & 29.9 & Ultra sonic, 2-way $16 \mathrm{MHz}$ \\
\hline$\overline{\mathrm{SOC}}$ & annular** & curved & $\mathrm{pvc}$ & 6.0 & 0.15 & 0.44 & 0.3 & 0.40 & 19.0 & 30.7 & ADV \\
\hline PML & annular ${ }^{\star \star}$ & curved & plexiglass & 0.5 & 0.10 & 0.36 & 0.3 & 0.06 & 15.0 & 30.0 & ADV $16 \mathrm{MHz}$ \\
\hline \multirow{3}{*}{ AWI } & field flume - control*k* & straight & $\mathrm{pvc}^{\star \star \star \star \star}$ & 1.6 & 0.87 & 0.31 & 2.8 & 0.43 & 18 & 28.5 & \multirow{3}{*}{$\begin{array}{l}\text { induction flow meter: Marsh- } \\
\text { McBirney, Model } 2000\end{array}$} \\
\hline & field flume - widening ${ }^{\star \star \star}$ & straight & prc ${ }^{\star \star \star \star *}$ & 1.6 & 1.81 & 0.22 & 8.2 & 0.64 & $\begin{array}{l}18 \\
18\end{array}$ & 28.5 & \\
\hline & field flume - narrowing ${ }^{\star \star \star}$ & straight & 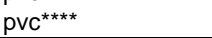 & 1.6 & 0.92 & 0.36 & 2.6 & 0.53 & 18 & 28.5 & \\
\hline
\end{tabular}

* Measurement in the centre of the channel at the end of the tet section in straight and racetrack flumes ${ }^{*}$ For the annular flumes, length refers to the diameter

test section have been taken into account

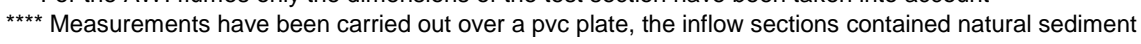


Table 3: Local and channel Reynolds numbers for the different laboratory flumes at high and low flow velocity.

\begin{tabular}{|c|c|c|c|c|}
\hline \multicolumn{5}{|c|}{ Flume Re } \\
\hline & \multicolumn{2}{|c|}{$0.05 \mathrm{~m} \mathrm{~s}^{-1}$} & \multicolumn{2}{|c|}{$0.25 \mathrm{~m} \mathrm{~s}^{-1}$} \\
\hline & $\boldsymbol{R} \mathbf{e}_{\mathrm{x}}$ & $\mathbf{R e}_{\mathrm{c}}$ & $\boldsymbol{R} \mathbf{e}_{\mathrm{x}}$ & $\operatorname{Re}_{c}$ \\
\hline \multicolumn{5}{|c|}{ Straight flumes } \\
\hline GML & $3.510^{5}$ & $7.510^{3}$ & $1.7510^{6}$ & $3.7510^{4}$ \\
\hline TMBL & $2.7510^{5}$ & $1.2510^{4}$ & $1.37510^{6}$ & $6.2510^{4}$ \\
\hline MPI-MM & $2.710^{5}$ & $1.1910^{4}$ & $1.3510^{6}$ & $5.9410^{4}$ \\
\hline CREMA & $1.510^{5}$ & $1.010^{4}$ & $7.510^{5}$ & $5.010^{4}$ \\
\hline Rostock & $1.510^{5}$ & $1.010^{4}$ & $7.510^{5}$ & $5.010^{4}$ \\
\hline KUCORPI & $1.1510^{5}$ & $1.1910^{4}$ & $5.7510^{5}$ & $5.9410^{4}$ \\
\hline LOB & $8.510^{4}$ & $1.010^{4}$ & $4.2510^{5}$ & $5.010^{4}$ \\
\hline \multicolumn{5}{|c|}{ Race-track flumes } \\
\hline $\mathrm{NIOO}$ & $4.510^{5}$ & $1.510^{4}$ & $2.2510^{6}$ & $7.510^{4}$ \\
\hline MNHN & $3.010^{5}$ & $1.2510^{4}$ & $1.510^{6}$ & $6.2510^{4}$ \\
\hline \multicolumn{5}{|c|}{ Annular flumes } \\
\hline SOC & $N / A$ & $3.7510^{3}$ & $N / A$ & $1.87510^{4}$ \\
\hline PML & $\mathrm{N} / \mathrm{A}$ & $2.510^{3}$ & $\mathrm{~N} / \mathrm{A}$ & $1.2510^{4}$ \\
\hline
\end{tabular}


Table 4: boundary layer thickness and boundary layer Reynolds number.

\begin{tabular}{|c|c|c|c|c|c|c|c|c|}
\hline & \multicolumn{4}{|c|}{ velocity profile: $0.05 \mathrm{~m} \mathrm{~s}^{-1}$} & \multicolumn{4}{|c|}{ velocity profile: $0.25 \mathrm{~m} \mathrm{~s}^{-1}$} \\
\hline & $H(m)$ & $\delta(\mathrm{m})$ & $\delta / H$ & $\mathbf{R e}_{\delta}$ & $H(m)$ & $\delta(\mathrm{m})$ & $\delta / H$ & $\mathbf{R e}_{\delta}$ \\
\hline \multicolumn{9}{|l|}{ Straight flumes } \\
\hline$\overline{G M L}$ & 0.24 & 0.03 & 0.13 & 1500 & 0.24 & 0.03 & 0.13 & 7500 \\
\hline TMBL & 0.13 & $>0.06$ & $>0.48$ & 3000 & 0.13 & $>0.06$ & $>0.48$ & 15000 \\
\hline CREMA & 0.15 & $0.06^{*}$ & 0.40 & 3000 & 0.15 & $>0.10$ & 0.69 & 25750 \\
\hline Rostock & 0.20 & 0.05 & 0.25 & 2500 & 0.14 & $\mathrm{nc}$ & $\mathrm{nc}$ & \\
\hline KUCORPI & 0.15 & 0.07 & 0.45 & 3400 & 0.15 & 0.06 & 0.39 & 14750 \\
\hline MPI-MM & 0.20 & 0.10 & 0.50 & 5000 & 0.20 & 0.10 & 0.50 & 25000 \\
\hline IRPHE & 0.10 & 0.09 & 0.90 & 4500 & 0.10 & 0.10 & 1.00 & 25000 \\
\hline \multicolumn{9}{|l|}{ Race-track flumes } \\
\hline $\mathrm{NIOO}$ & 0.39 & 0.15 & 0.38 & 7500 & 0.39 & 0.15 & 0.38 & 37500 \\
\hline MNHN & 0.15 & 0.08 & 0.50 & 3750 & 0.15 & 0.14 & 0.93 & 35000 \\
\hline \multicolumn{9}{|l|}{ Annular flumes } \\
\hline SOC & 0.44 & 0.01 & 0.02 & 500 & 0.44 & $\mathrm{nc}$ & $\mathrm{nc}$ & \\
\hline PML & 0.36 & 0.01 & 0.03 & 500 & 0.36 & 0.005 & 0.01 & 1250 \\
\hline \multicolumn{5}{|l|}{ Field flumes ${ }^{* *}$} & & & & \\
\hline AWI - control $\left(0.07 \mathrm{~m} \mathrm{~s}^{-1}\right)$ & 0.31 & 0.07 & 0.23 & 4900 & & & & \\
\hline AWI - widening $\left(0.05 \mathrm{~m} \mathrm{~s}^{-1}\right)$ & 0.22 & 0.22 & 1 & 11000 & & & & \\
\hline AWI - narrowing $\left(0.15 \mathrm{~m} \mathrm{~s}^{-1}\right)$ & 0.36 & 0.20 & 0.56 & 30000 & & & & \\
\hline
\end{tabular}

* Velocity $0.08 \mathrm{~m} \mathrm{~s}^{-1}$

$\mathrm{nc}=$ not calculated

**boundary layer thickness data are rough estimates, since velocities decline towards the surface.

Maximum flow velocities are taken as free-stream velocities 
Legends to the figures

Figure 1: Schematic overview of four types of flume tanks included in this study. A: straight, B: racetrack, C: annular, D: field flumes.

Figure 2: Velocity profiles at $0.05 \mathrm{~m} \mathrm{~s}^{-1}$ free-stream velocity in all the flumes and all the field flume measurements. Horizontal lines indicate the water level. In the AWI-field flume graph triangles represent the widening (decelerating) channel, diamonds represent the control channel and squares represent the narrowing (accelerating) channel.

Figure 3: Velocity profiles at $0.25 \mathrm{~m} \mathrm{~s}^{-1}$ free-stream velocity in all the flumes. Horizontal lines indicate the water level.

Figure 4: Velocity profiles measured in the field.

Figure 5: $\quad r^{2}$ values for the log-linear relationship between height above the bed and horizontal velocity.

Figure 6: Estimates of shear velocity (mean $\pm 95 \% \mathrm{CI}$ ) at 0.05 and $0.25 \mathrm{~m} \mathrm{~s}^{-1}$, based on the slope of the law-of-the-wall regression.

Figure 7: $\quad$ Estimates of roughness length (mean $\pm 95 \% \mathrm{CI}$ ) at 0.05 and $0.25 \mathrm{~m} \mathrm{~s}^{-1}$, based on the y-intercept of the law-of-the-wall regression.

Figure 8: $\quad$ Plot of all velocity profiles from the straight and racetrack flumes using the dimensionless numbers $\mathrm{z}^{+}$and $\mathrm{u}^{+}$(see Table 1 for explanation). A: Results for all the flumes with a straight working section and B: results from the field measurements.

Figure 9: Turbulence intensity at $0.05 \mathrm{~m}$ above the bottom surface and at $20 \%$ of the water depth, at 0.05 (A) and 0.25 (B) $\mathrm{m} \mathrm{s}^{-1}$ free-stream velocity.

Figure 10: Turbulent kinetic energy (TKE) at $0.05 \mathrm{~m}$ above the bottom surface and at $20 \%$ of the water depth, at 0.05 (A) and 0.25 (B) $\mathrm{m} \mathrm{s}^{-1}$ free-stream velocity. Turbulent kinetic energy (TKE) normalised with local flow velocity at $0.05 \mathrm{~m}$ above the bottom surface and at $20 \%$ of the water depth, at 0.05 (C) and 0.25 (D) $\mathrm{m} \mathrm{s}^{-1}$ free-stream velocity.

Figure 11: Reynolds stress $\left(-\rho \overline{u^{\prime} w^{\prime}}\right)$ at $0.05 \mathrm{~m}$ above the bed, and at $20 \%$ of the water depth, at 0.05 (A) and 0.25 (B) $\mathrm{m} \mathrm{s}^{-1}$ free-stream velocity. Reynolds stress normalised with local flow velocity $\left(\frac{-\overline{u^{\prime} w^{\prime}}}{u^{2}+v^{2}+w^{2}}\right)$ at $0.05 \mathrm{~m}$ above the bed 
and at $20 \%$ of the water depth, at 0.05 (C) and 0.25 (D) $\mathrm{m} \mathrm{s}^{-1}$ free-stream velocity.

Figure 12: Normalised Reynolds stress $\frac{-\overline{u^{\prime} w^{\prime}}}{\left(u_{\infty}\right)^{2}}$ in relation to $z / \delta$ above the bottom at high and low flow velocity.

Figure 13: A: $\mathrm{u}_{*}$ estimates based on TKE data against $\mathrm{u}_{*}$ estimates based on Reynolds stress data (covariance method). Black circles: flume data at $0.05 \mathrm{~m} \mathrm{~s}^{-1}$, white circles flume data at $0.25 \mathrm{~m} \mathrm{~s}^{-1}$, grey circles: field data.

B: $\mathrm{u} *$ estimates derived from covariance method and TKE method against estimates from the slope of the log-linear profiles. Dark symbols: covariance method, open symbols: TKE method. Circles: flume measurements, stars: field data.

C: as in B, only using measurements taken inside the boundary layer.

Figure 14: Spectral density plots of the autocorrelation of the $\mathbf{u}$ velocity component, at 5 $\mathrm{cm}$ above the bottom.

Figure 15: Relationship between flume width and upper turbulence scales $\left(r^{2}=0.24, p=\right.$ 0.06) ignoring one outlier. Relationship between flume width and upper turbulence scales $\left(r^{2}=0.24, p=0.06\right)$ ignoring one outlier.

Figure 16: $\quad$ Correlation between the $v^{\prime}$ and $w^{\prime}$ components, indicative of secondary flows. 


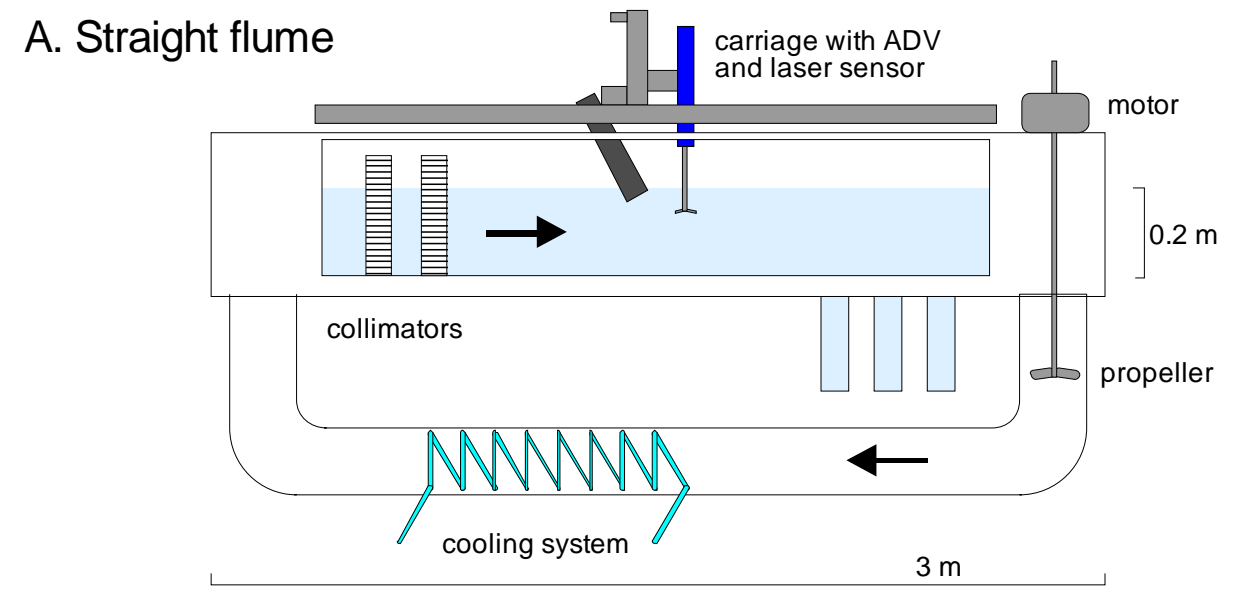

\section{B. Race-track flume}

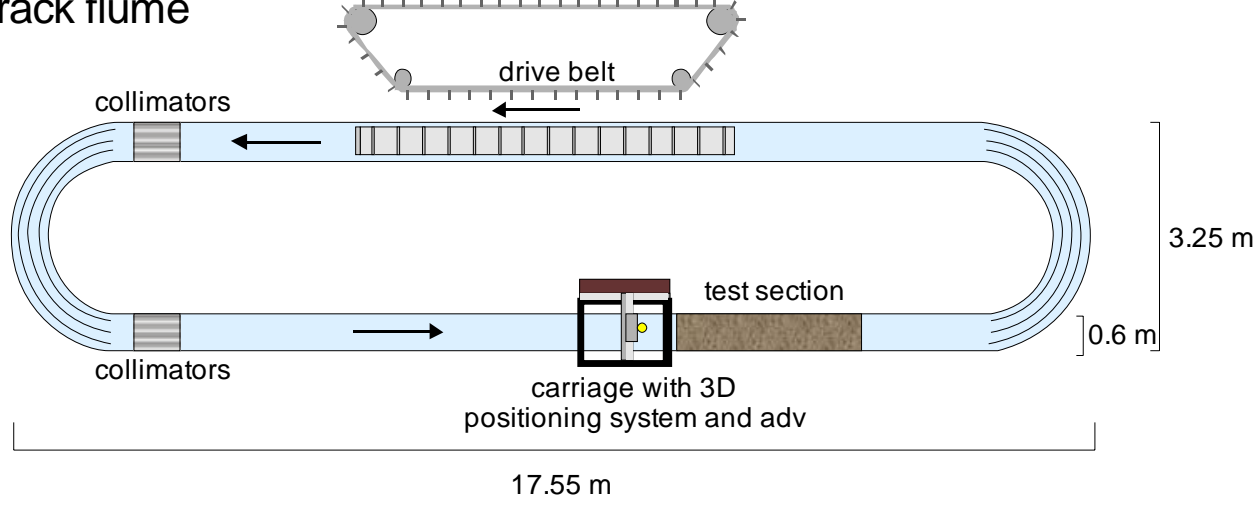

\section{Annular Flume}
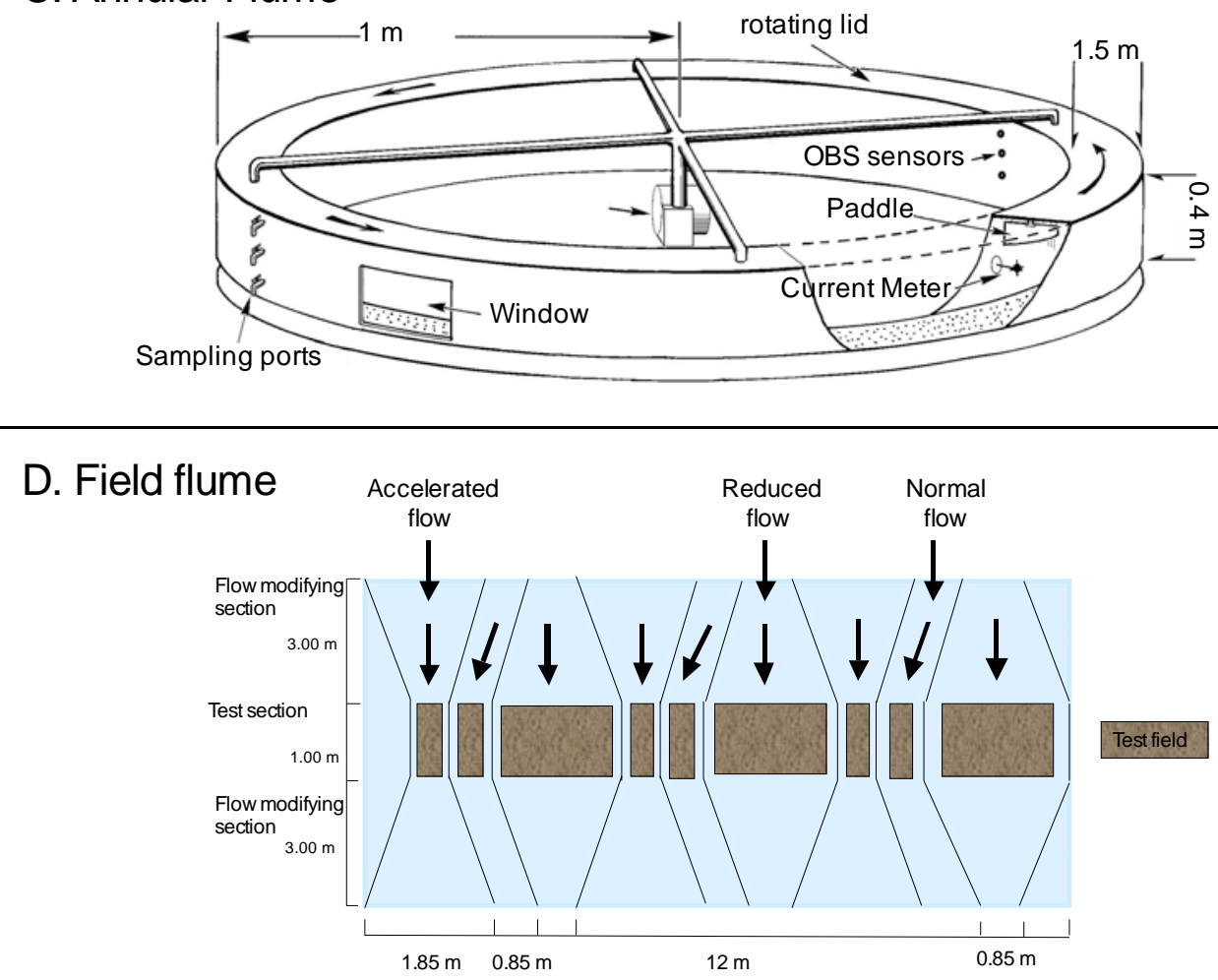

Figure 1 


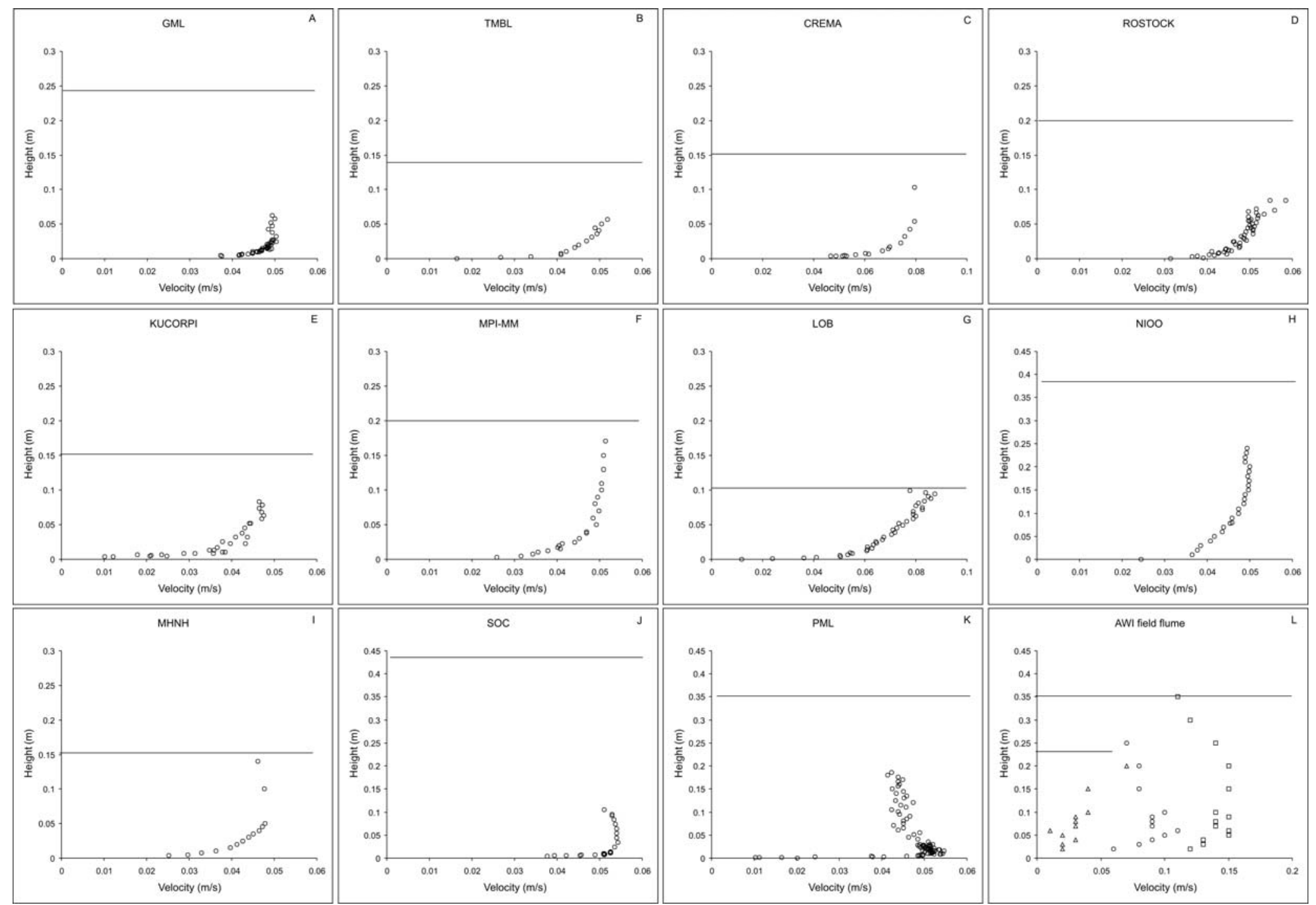

Figure 2 


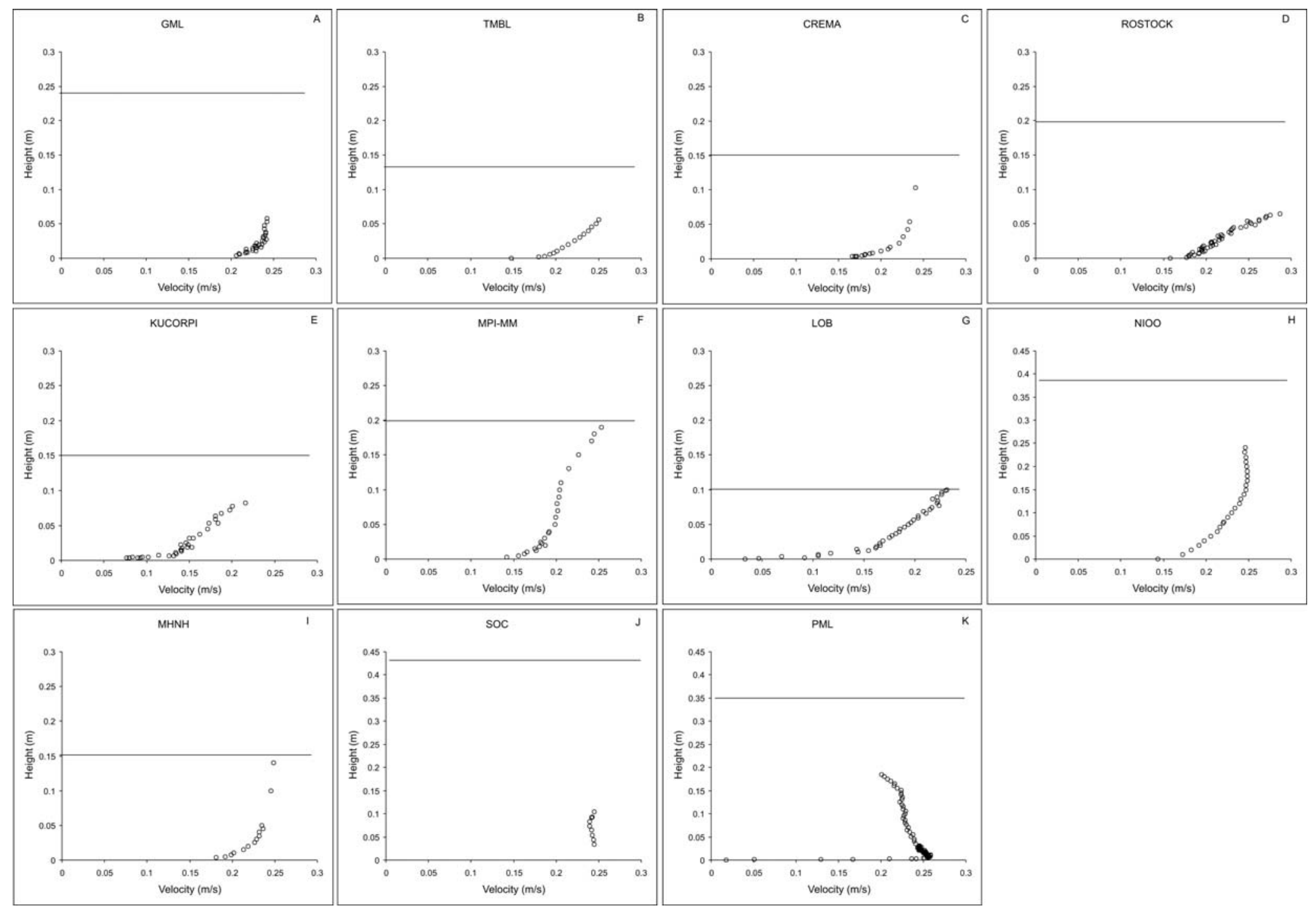

Figure 3 

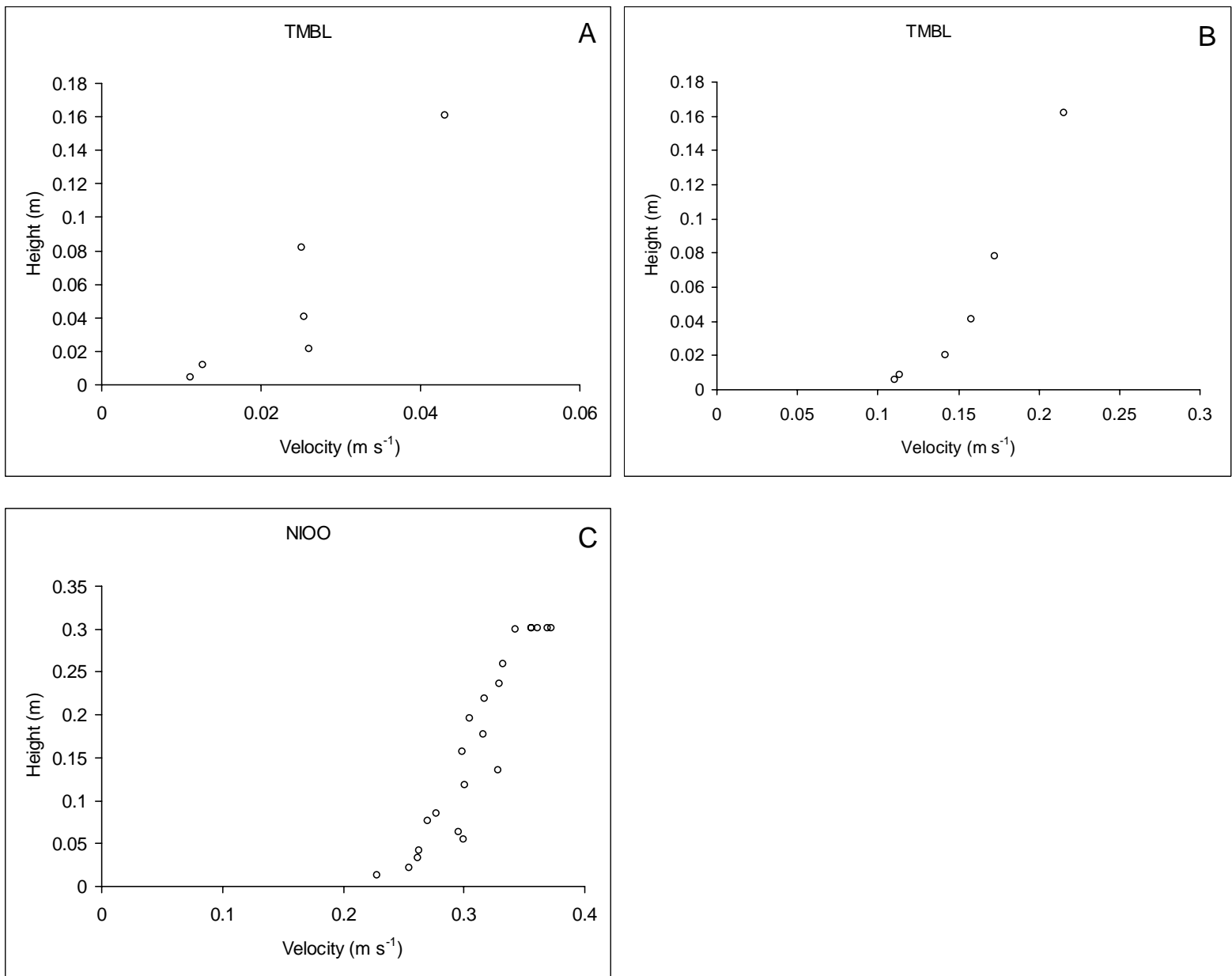

Figure 4 


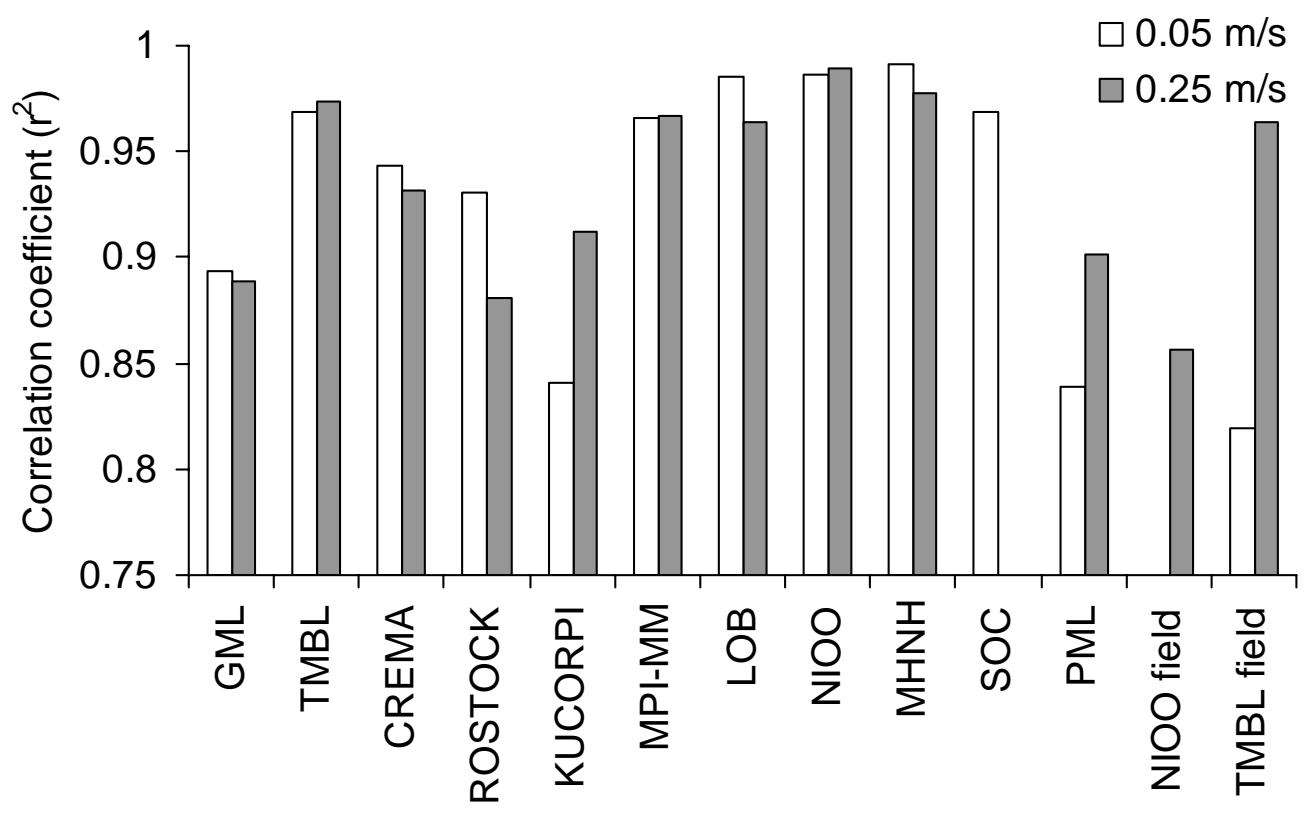

Figure 5 


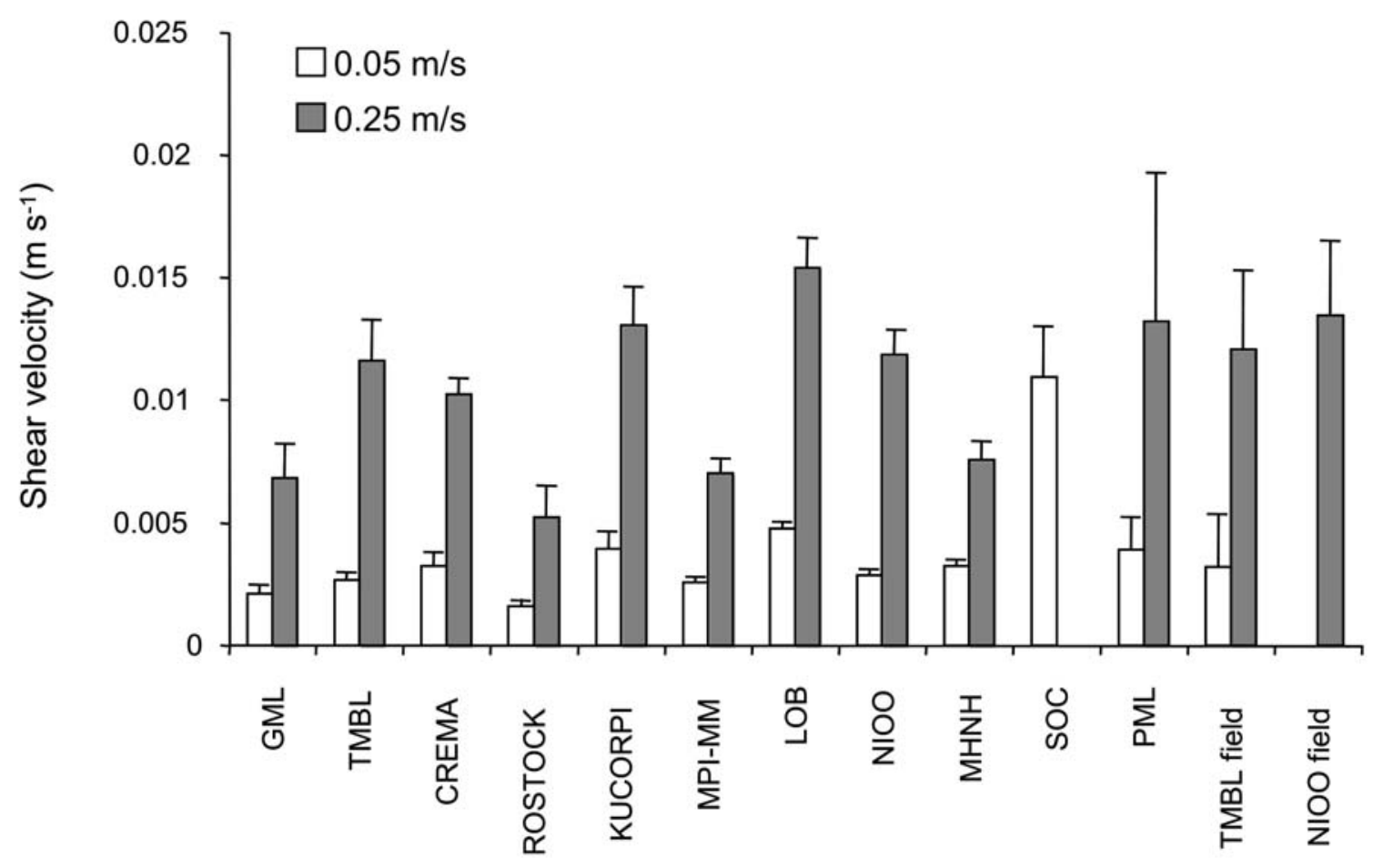

Figure 6 


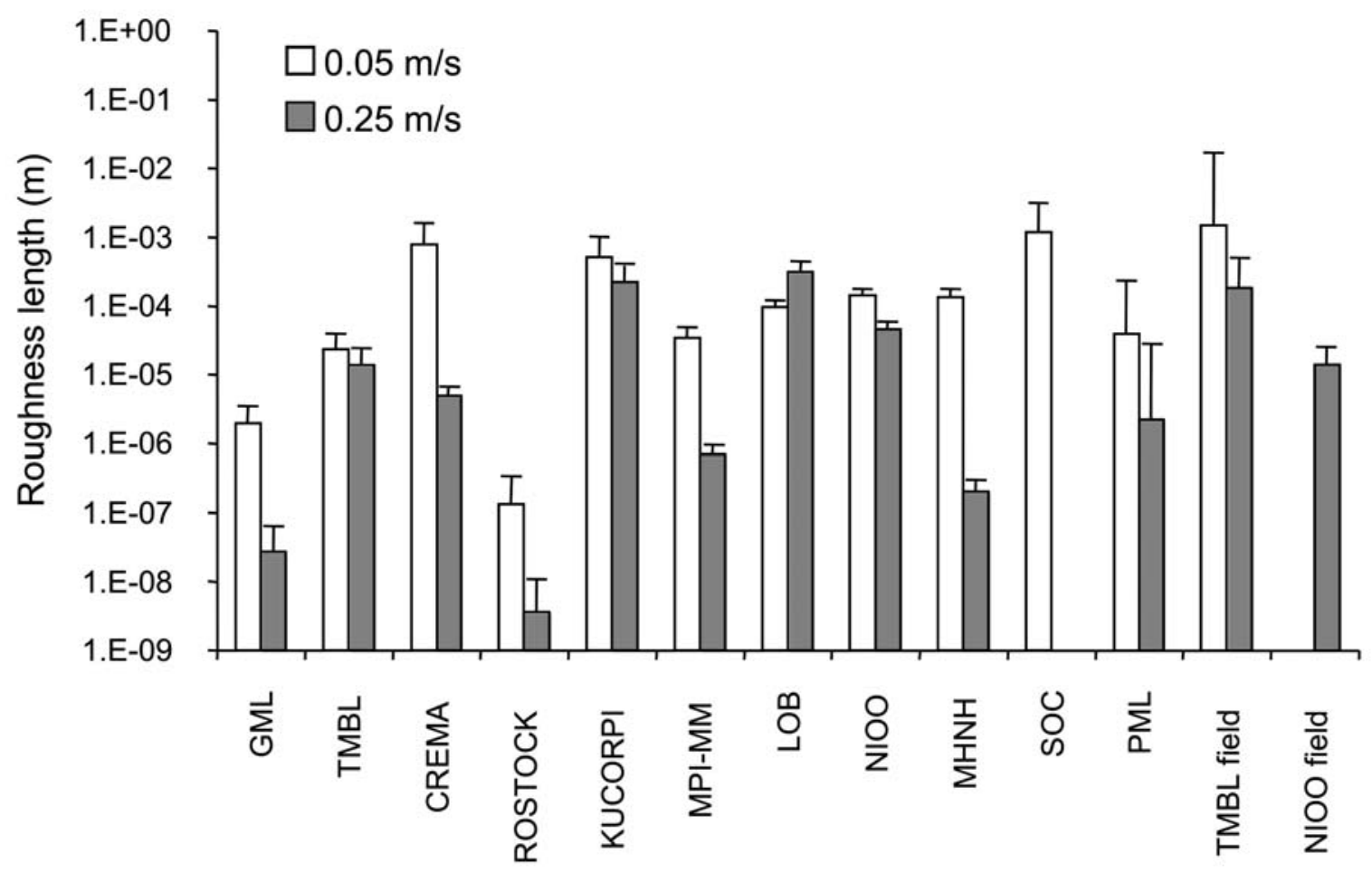

Figure 7 


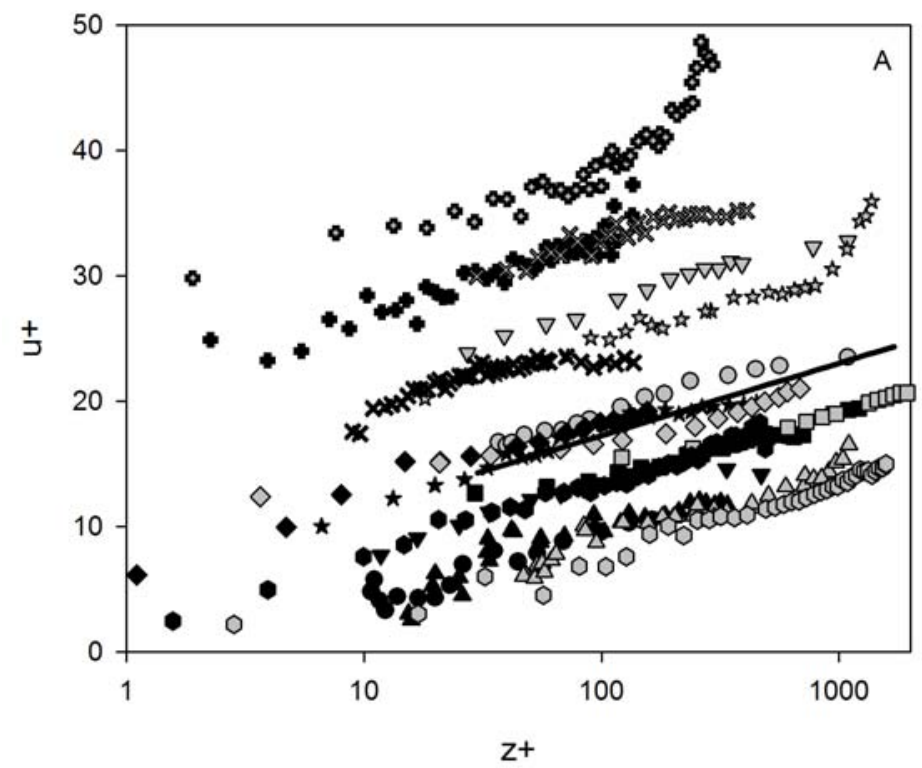

- CREMA - $0.05 \mathrm{~m} / \mathrm{s}$

O CREMA $-0.25 \mathrm{~m} / \mathrm{s}$

- KUCORPI $-0.05 \mathrm{~m} / \mathrm{s}$

$\triangle$ KUCORPI $-0.25 \mathrm{~m} / \mathrm{s}$

- MNHN $-0.05 \mathrm{~m} / \mathrm{s}$

$\nabla \quad \mathrm{MNHN}-0.25 \mathrm{~m} / \mathrm{s}$

* MPI-MM $-0.05 \mathrm{~m} / \mathrm{s}$

* MPI-MM $-0.25 \mathrm{~m} / \mathrm{s}$

- $\mathrm{NIOO}-0.05 \mathrm{~m} / \mathrm{s}$

ㅁ $\mathrm{NIOO}-0.25 \mathrm{~m} / \mathrm{s}$

$\rightarrow$ TMBL $-0.05 \mathrm{~m} / \mathrm{s}$

$\diamond T M B L-0.25 \mathrm{~m} / \mathrm{s}$

- ROSTOCK $-0.05 \mathrm{~m} / \mathrm{s}$

- ROSTOCK $-0.25 \mathrm{~m} / \mathrm{s}$

- LOB $-0.05 \mathrm{~m} / \mathrm{s}$

- LOB $-0.25 \mathrm{~m} / \mathrm{s}$

$\times \quad \mathrm{GML}-0.05 \mathrm{~m} / \mathrm{s}$

$\times \quad \mathrm{GML}-0.25 \mathrm{~m} / \mathrm{s}$

Theoretical boundary layer

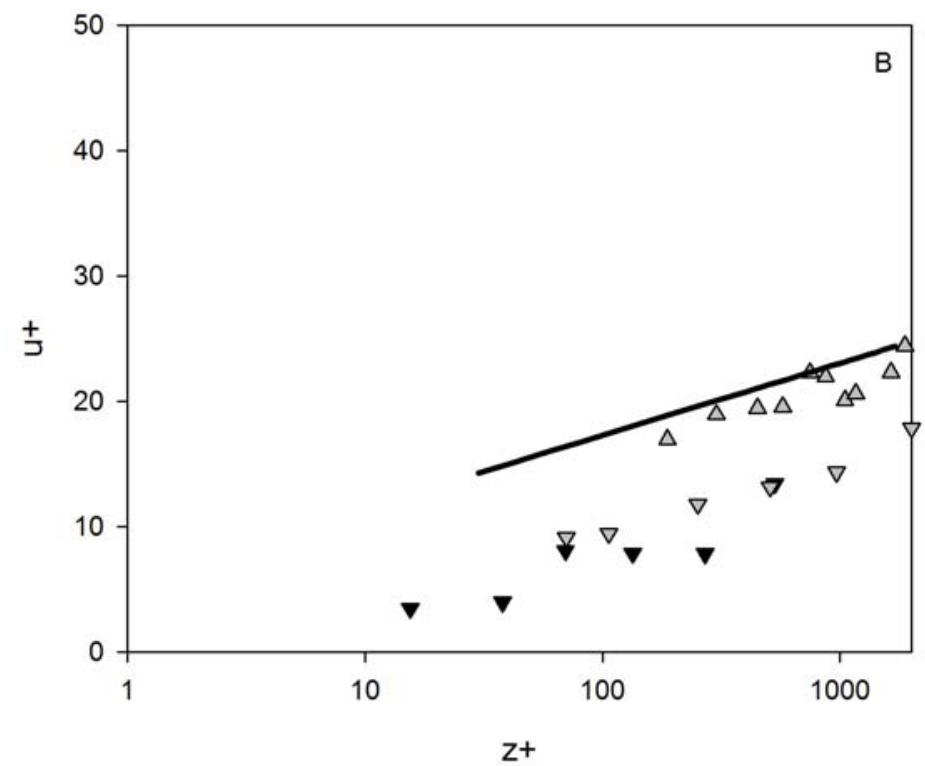

$\triangle \quad$ NIOO field measurements

- TMBL field measurements (low velocity)

$\nabla$ TMBL field measurments (high velocity) Theoretical boundary layer

Figure 8 

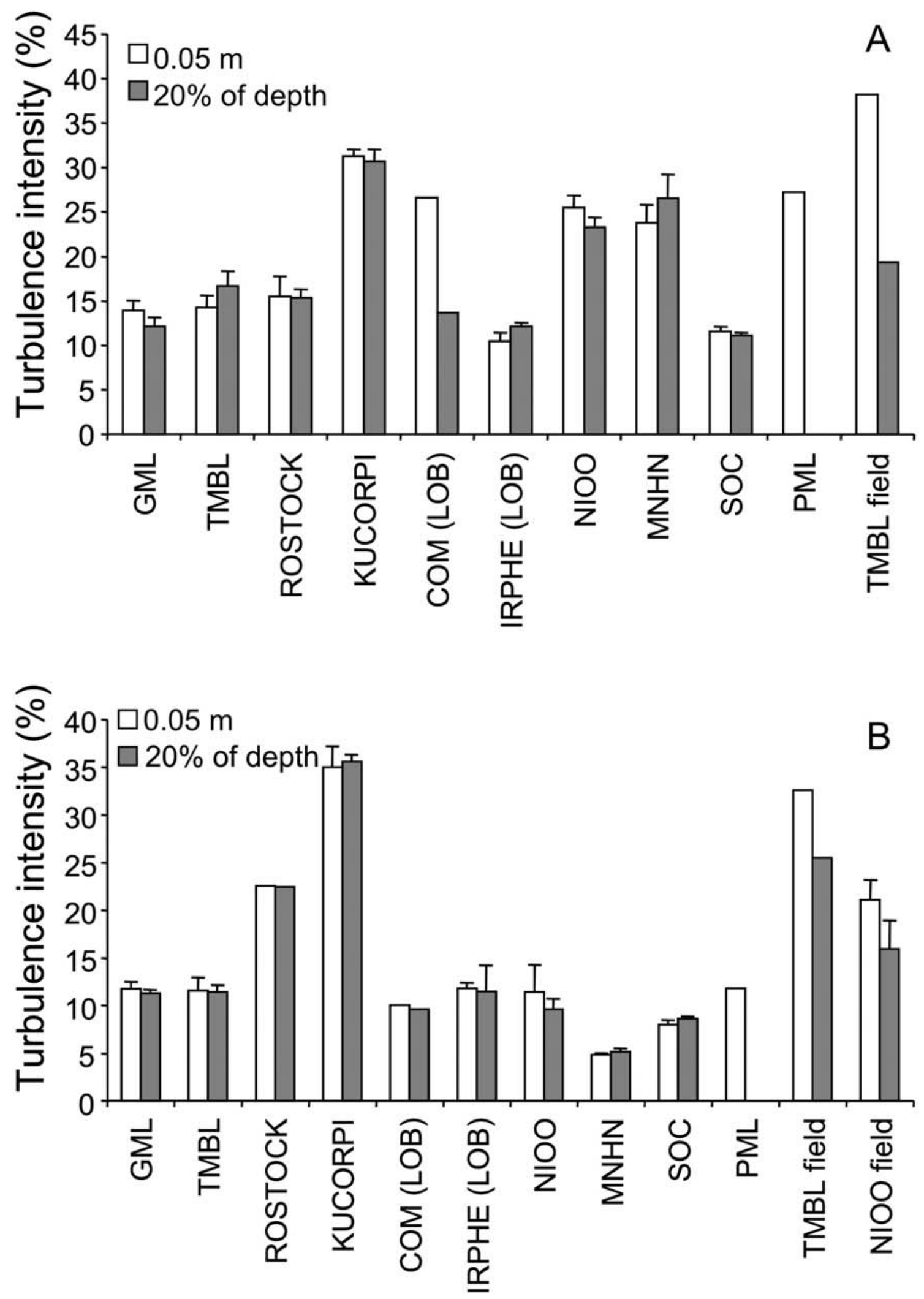

Figure 9 

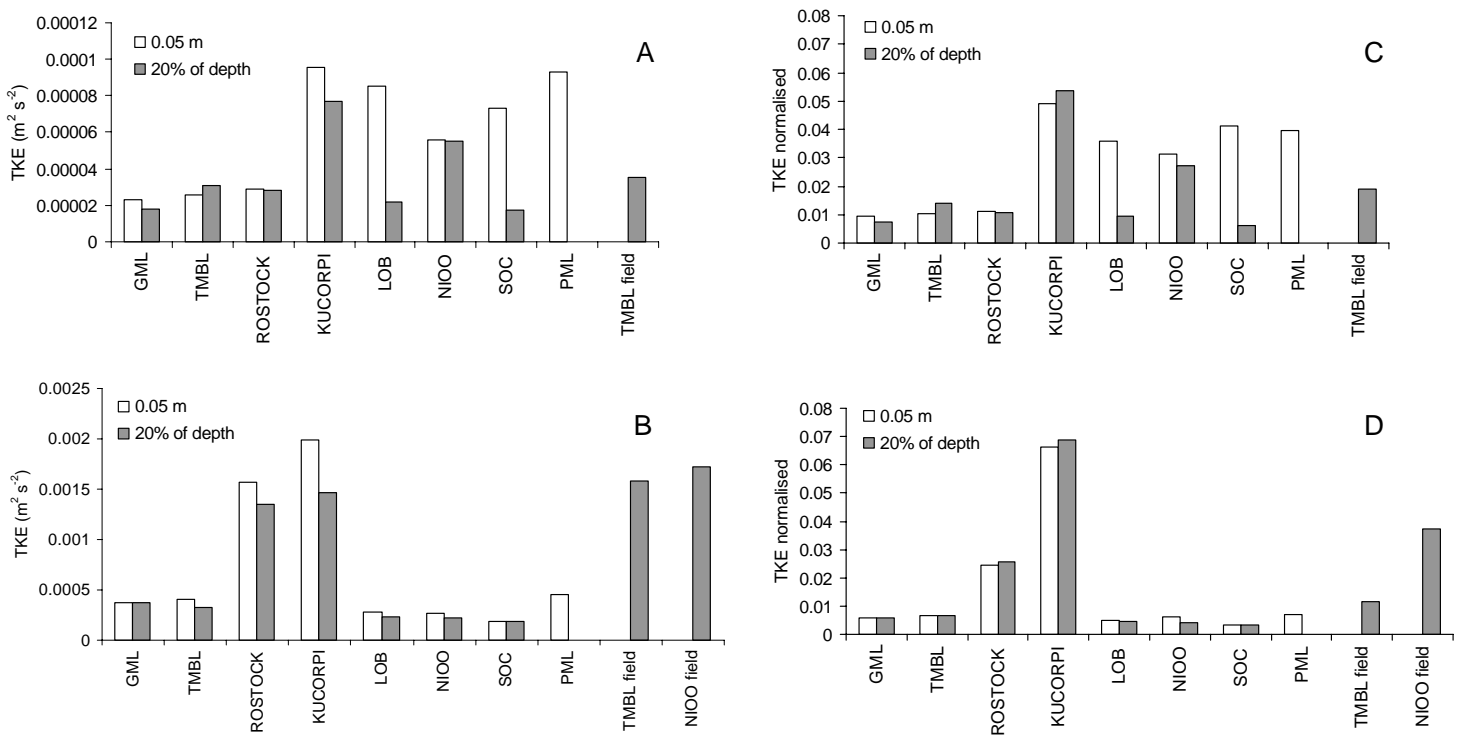

Figure 10 

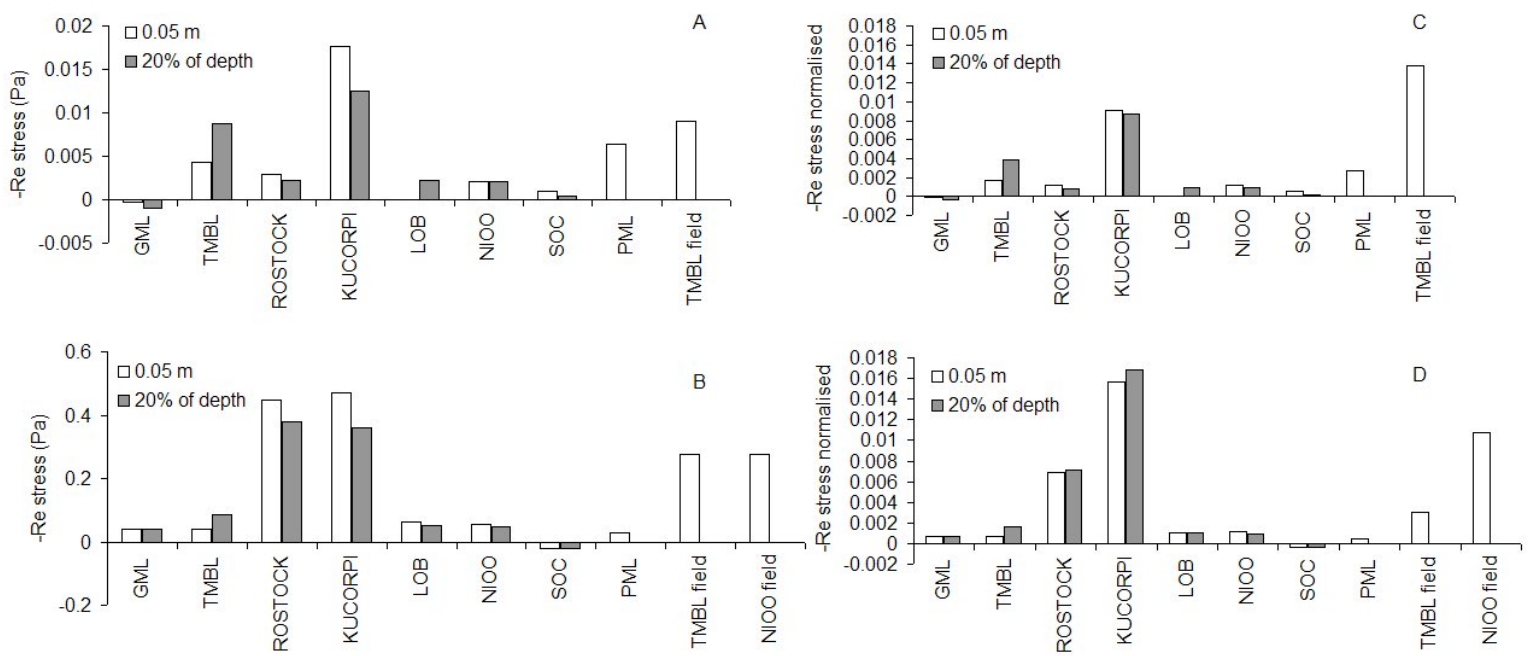

Figure 11 


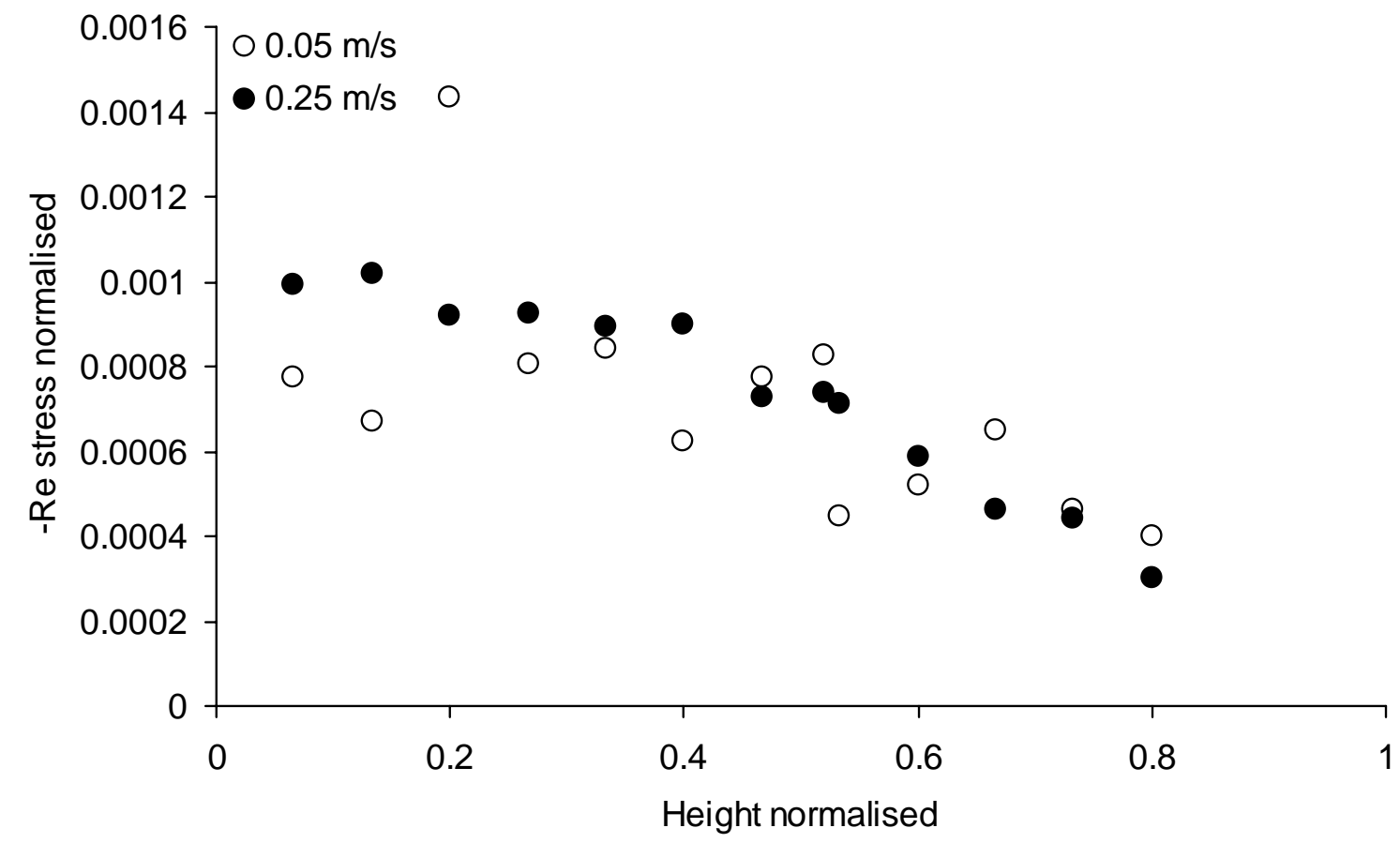

Figure 12 

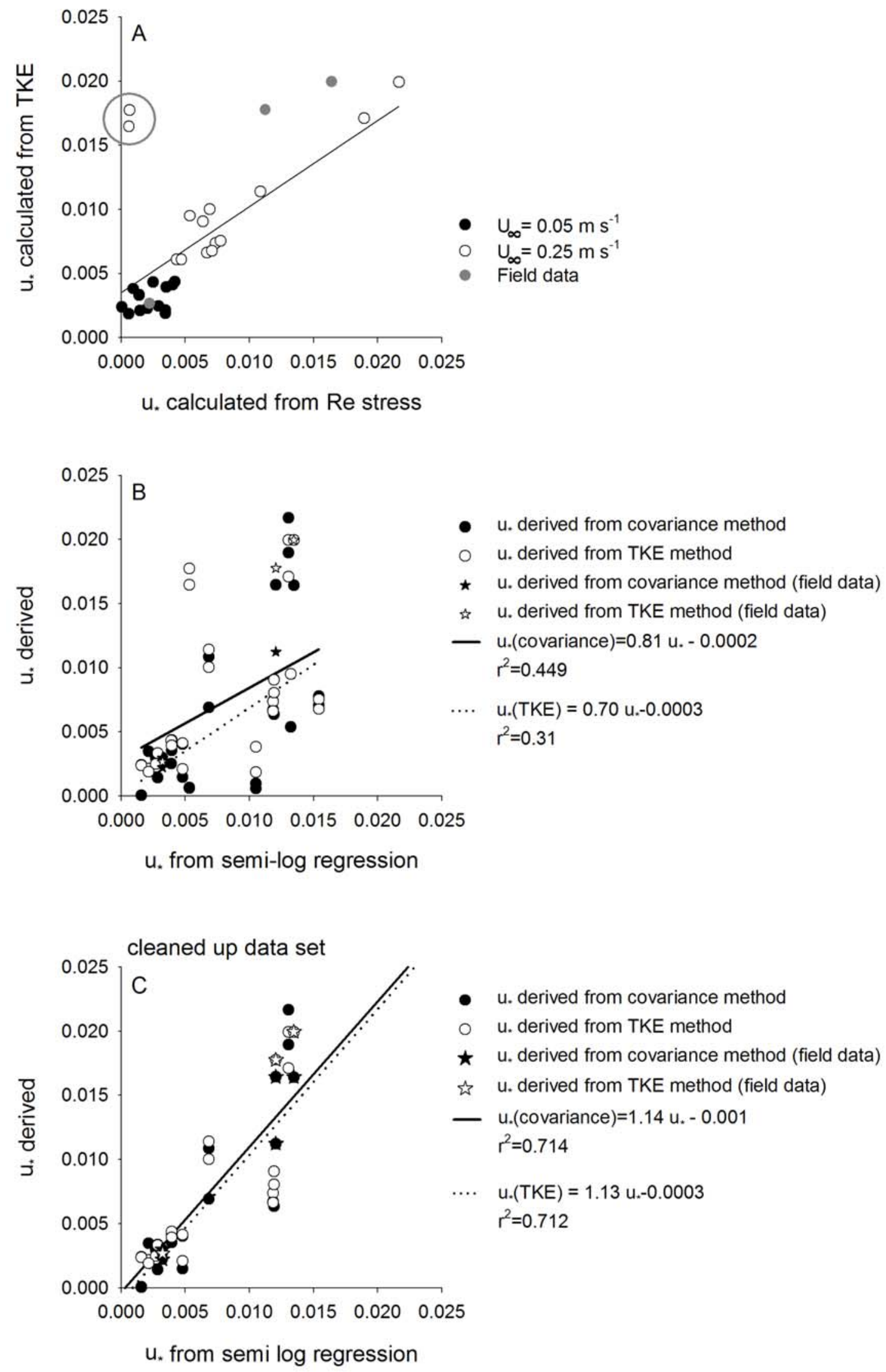

Figure 13 


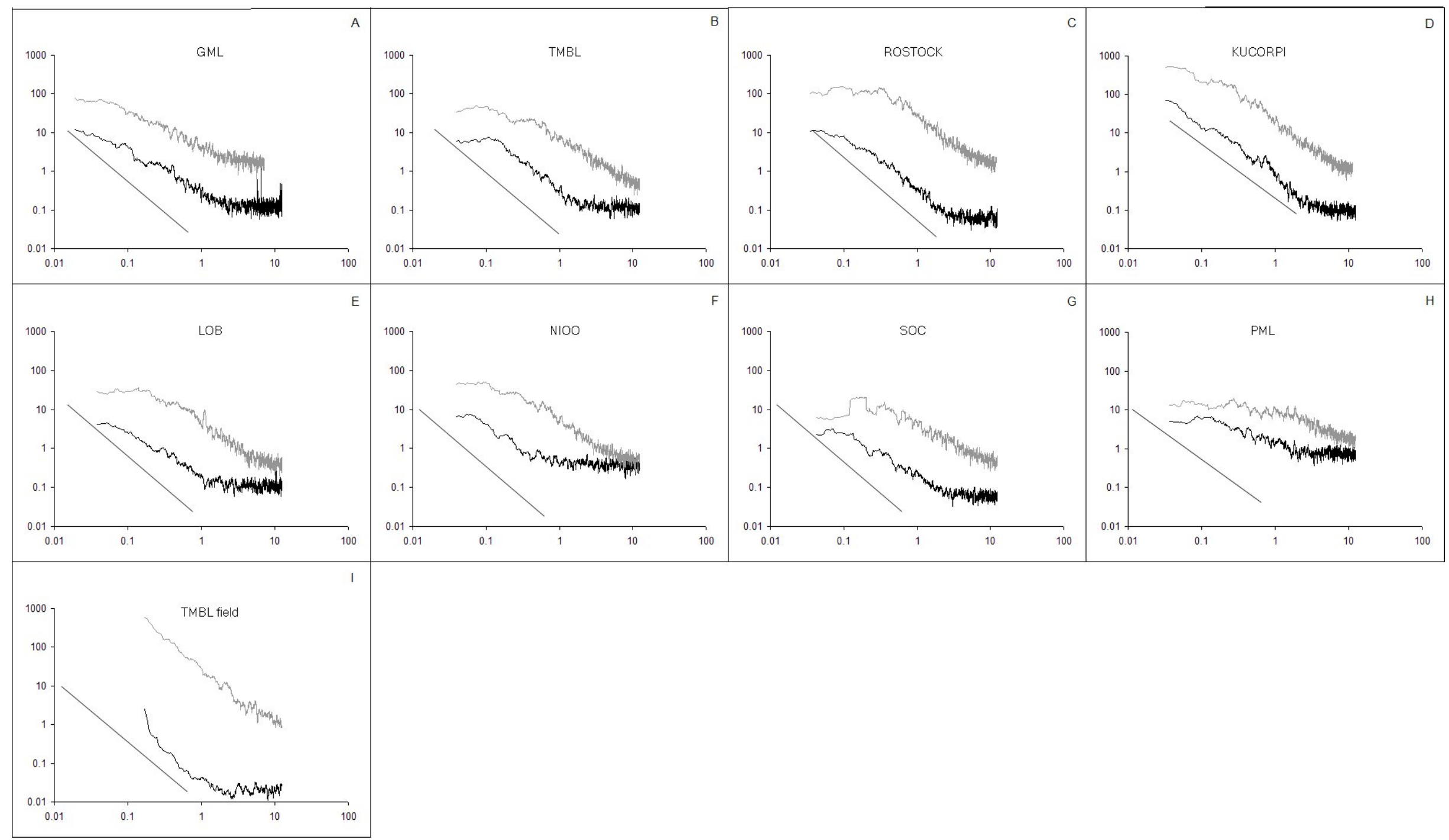

Figure 14 


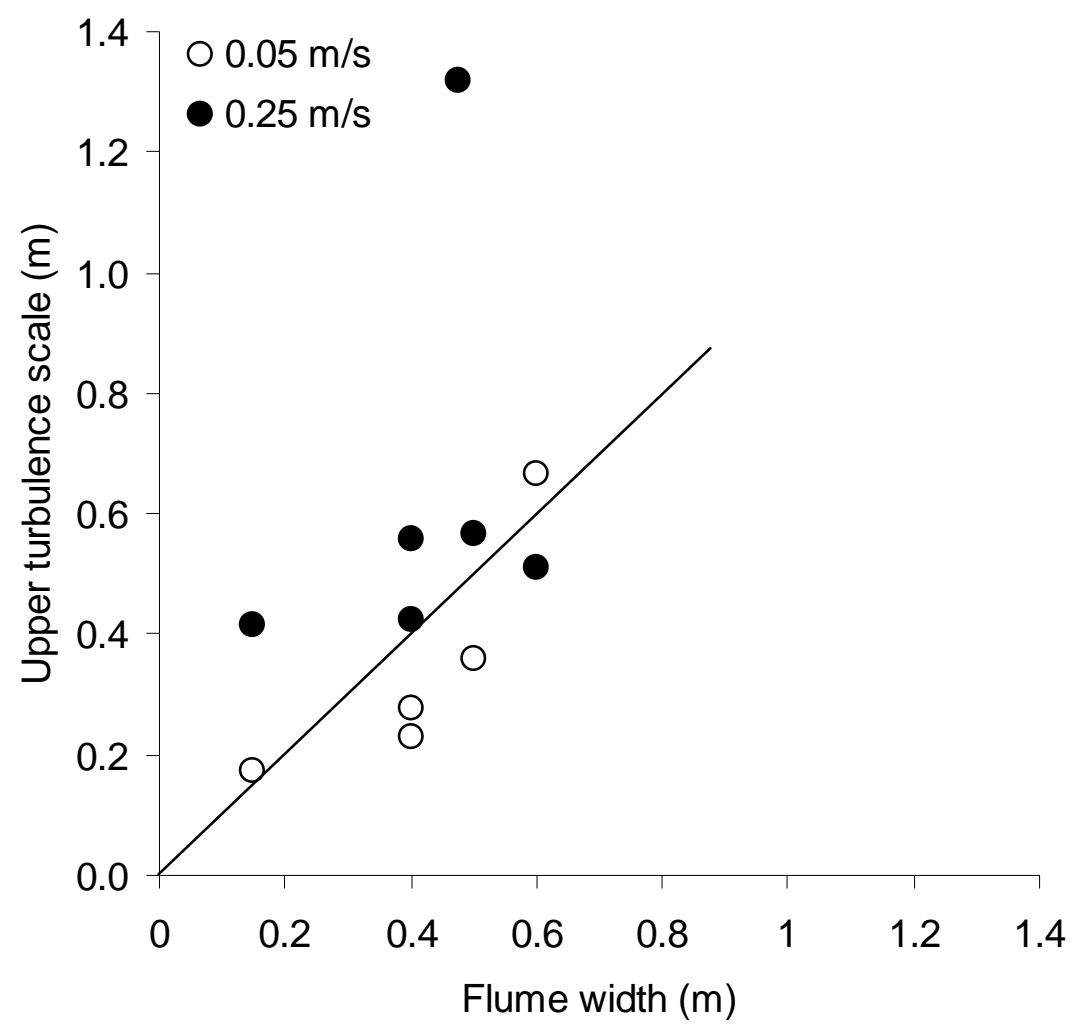

Figure 15 


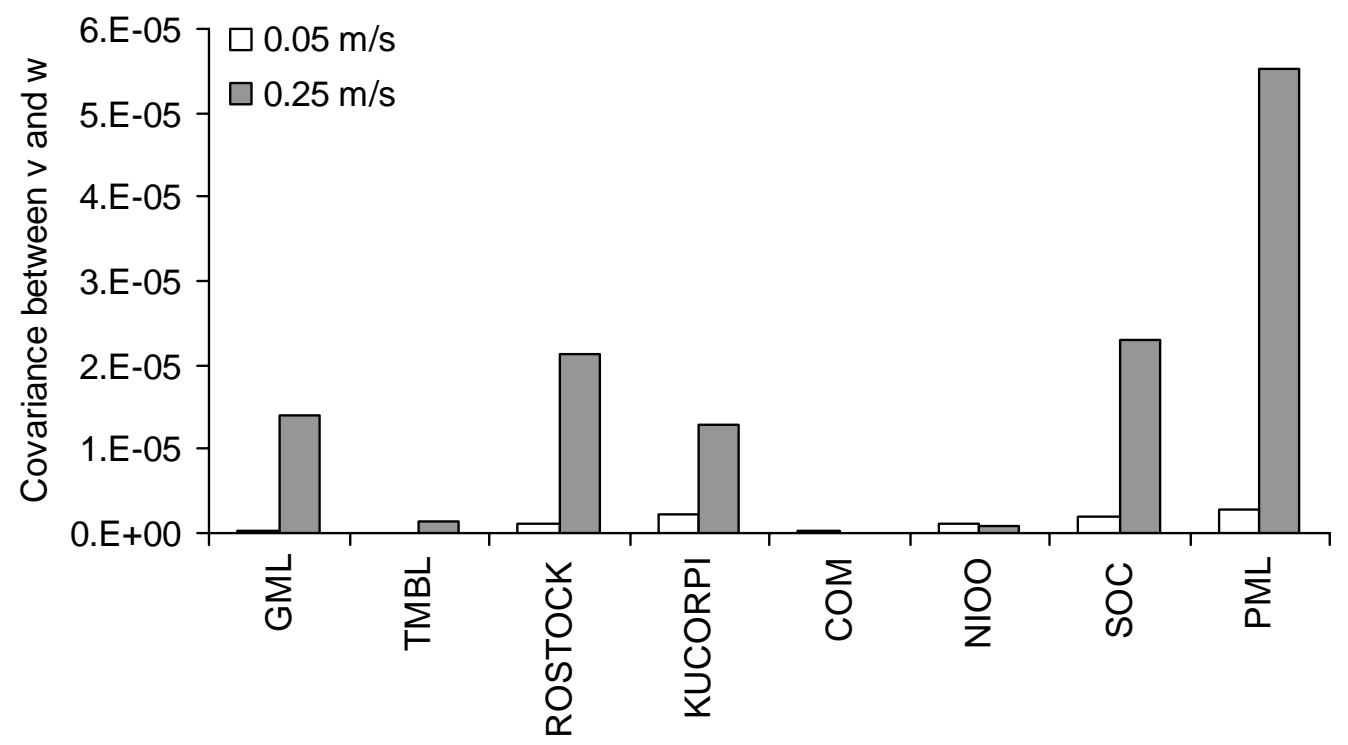

Figure 16 